\title{
LA CONSTRUCCIÓN DEL PAISAJE AGRÍCOLA PREHISPÁNICO EN LOS ANDES COLOMBIANOS: EL CASO DE LA SABANA DE BOGOTÁ
}

\author{
THE CONSTRUCTION OF THE PRE-HISPANIC AGRICULTURAL LANDSCAPE IN \\ THE COLOMBIAN ANDES: THE CASE OF THE SABANA DE BOGOTÁ
}

\author{
LORENA RODRÍGUEZ GALLO
}

Historiadora, PhD en Arqueología. Docente Investigador Universidad Manuela Beltrán Calle 77A No. 114A 58, Bogotá-Colombia. Correo-e: lorenarupestre@gmail.com. (D) https://orcid.org/0000-0002-1437-4703

\begin{abstract}
Resumen: El sistema hidráulico de campos elevados de cultivo o camellones, construido a lo largo de 2500 años por los grupos prehispánicos de la Sabana de Bogotá, Colombia, es el tema central del presente artículo. El análisis está enfocado en la relación establecida entre estos grupos y el agua, para determinar de qué manera la interacción entre ambos llevó a una forma particular de construcción del paisaje agrícola, de aprovechamiento de los recursos y de ocupación del territorio, durante el período Muisca Tardío (1000 d.C. - 1550 d.C.). Apoyados en los conceptos de la arqueología del paisaje, en los datos arqueológicos, paleoambientales, en la fotointerpretación y en la documentación colonial, pudimos establecer que el sistema de camellones fue el resultado de la interrelación hombre-ambiente, en que los hombres crearon una forma de vivir en un ambiente inundable, haciendo del agua el eje y la red de conexión entre canales, plataformas para el cultivo, asentamientos, áreas de caza y pesca y zonas de mitigación.

Palabras clave: Camellones, Sabana de Bogotá, agricultura prehispánica, Muiscas, manejo del agua, arqueología del paisaje.
\end{abstract}

Summary: The Hydraulic System of Raised Fields of Cultivation or Camellones, built for over 2500 years by the preHispanic groups of the Sabana de Bogotá, Colombia, is the central theme of this article. The analysis is focused on the relationship established between these groups and water, to determine how the interaction between the two led to a particular form of construction of the agricultural landscape, resource utilization and land occupation during the Late Muisca period (1000 - 1550 AD). Based on the concepts of landscape archeology, on archaeological and paleo-environmental data, photointerpretation and colonial documentation, we were able to establish that the system of camellones was the result of man-environment interaction, in which men created a way of living in a floodable environment by making water the axis and the network of connection between channels, cultivation platforms, settlements, hunting, fishing and mitigation areas.

Keywords: Camellones, Sabana de Bogotá, pre-Hispanic agriculture, Muiscas, water management 


\section{INTRODUCCIÓN}

El manejo del agua a través de la construcción de estructuras en tierra fue un elemento central de la organización de varios grupos prehispánicos de América, tanto en ambientes de montaña como en las tierras bajas tropicales, con el fin de facilitar la ocupación del territorio y de desarrollar prácticas agrícolas (Denevan 1970, Valdez 2006). En el presente artículo pretendemos analizar el sistema de manejo de agua construido en la Sabana de Bogotá por los grupos prehispánicos que allí se instalaron, a fin de comprender cómo las actividades de agricultura, caza, pesca y los lugares de habitación se integraron con el agua, abundante en esta planicie inundable, para crear un paisaje arqueológico específico.

La Sabana de Bogotá está localizada a $2.600 \mathrm{~m}$ de altura en la cordillera Oriental del sistema andino colombiano (fig. 1). Es una planicie de $1.413 \mathrm{~km}^{2}$ de extensión, que hace parte del altiplano Cundiboyacense. Posee un medio ecológico de bosque andino con alta presencia de agua, representada en reductos del lago que existió hace 30.000 años, una extensa red de valles erosivos, encharcamientos por alto nivel freático e

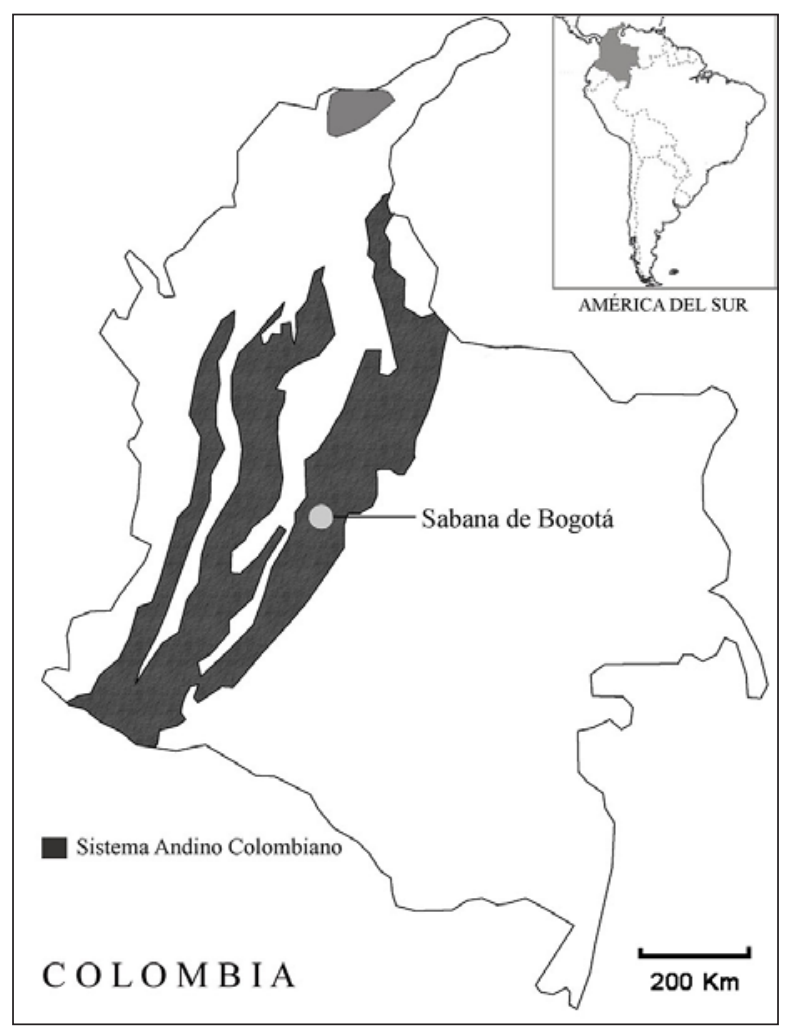

Figura. 1. Localización del área de estudio. inundaciones periódicas. Dadas estas condiciones, los grupos agrícolas de la Sabana comenzaron a construir hace 3.000 años un sistema de control de agua que les permitió vivir, sembrar y desarrollar su cotidianidad en esta planicie, y que se mantuvo activo hasta el momento de la invasión española.

Sin embargo, después del proceso de colonización, estas estructuras en tierra cayeron rápidamente en desuso y en el olvido, siendo redescubiertas solo en la segunda mitad del siglo XX, a partir del registro aerofotográfico. Desde entonces, algunas investigaciones se han ocupado de ellas, pero dada la gran extensión del sistema hidráulico, solo la realizada por Boada (2006) se ha enfocado en el análisis detallado de buena parte del sistema. El propósito del presente artículo es realizar un análisis pormenorizado del sistema de camellones, desde la perspectiva de la arqueología del paisaje, a fin de examinarlo de forma integrada y no solo como un sistema de producción agrícola. Por tanto, se busca comprender cómo se integró con la estructura ecológica de la Sabana, con otras actividades económicas (caza y pesca) y con los lugares de habitación de los grupos prehispánicos.

\section{MÉTODOS Y TÉCNICAS}

La metodología usada para tal fin fue la fotointerpretación de fotografías aéreas de la Sabana de Bogotá, tomadas por el IGAC (Instituto Geográfico Agustín Codazzi) entre 1938 y 1956, que suman 25 vuelos, realizadas con diferentes escalas que varían desde 1:3.000 a 1:24.000 y en diversas épocas del año (ver anexo 1). Esta riqueza de material permite una mejor identificación de los vestigios arqueológicos, porque disponemos de visualizaciones con diferentes incidencias de luz y mayor, menor o ninguna presencia de agua en el terreno según se trate de una época de sequía o de lluvias.

La fotointerpretación estuvo apoyada por los datos arqueológicos disponibles para la Sabana de Bogotá, particularmente los relativos a los grupos agrícolas (Herrera: 800 a.C. - 100 d.C.; Muisca Temprano: 100 d.C. -1000 d.C; Muisca Tardío: 1000 d.C. - 1550 d.C.); por la documentación colonial, específicamente del siglo XVI y XVII, en la que estuvieran presentes descripciones sobre el paisaje y ambiente ecológico de la Sabana de Bogotá, o en que se refirieran aspectos asociados al manejo del agua y a la agricultura entre los grupos indígenas en momentos previos o inmediatamente posteriores a la ocupación española; por cartografía antigua (siglos XVII, 
XVIII, XIX y primera mitad del siglo XX) que proveyera información sobre topografía y sobre elementos característicos del paisaje; y por los datos de paleo-ambiente relativos al contexto ecológico de la zona de estudio en momentos previos a la colonización y su transformación con la instalación de los españoles en ella.

Como el sistema hidráulico visible en las aerofotografías corresponde a su última fase de funcionamiento, su análisis estará restringido al periodo Muisca Tardío (1000 d.C. - 1550 d.C.), aunque se tendrán en cuenta los datos arqueológicos de toda la fase agrícola (Herrera y Muisca) para ayudar en la comprensión del proceso de ocupación y transformación del paisaje agrícola prehispánico de la Sabana de Bogotá.

\section{ASPECTOS TEÓRICOS: INTERPRETANDO LA SABANA A TRAVÉS DE LA ARQUEOLOGÍA DEL PAISAJE}

El paisaje es ante todo el producto de la compleja interrelación entre los grupos humanos y el medio ecológico que los abriga, y la arqueología del paisaje procura comprender esta interrelación en el pasado (Erickson 2010: 621). El espacio no puede ser entendido como un escenario donde el drama humano ocurre, sino como un territorio construido a través del diálogo permanente entre el medio ecológico y los hombres (Balée 1998, McIntosh 2005). Estas interrelaciones son dialécticas, es decir, que tanto la manera en que los hombres perciben el espacio a su alrededor y lo ocupan influirá en el modo como el espacio sea definido y aprovechado, así como los trazos particulares del medio condicionarán las formas que esas transformaciones van a adoptar. No hay en este sentido un medio ecológico intocado. En diferentes grados y con diversas consecuencias, todos los grupos humanos han transformado su entorno en un esfuerzo por construir sus propias vidas, a lo largo de varias generaciones en las que se han ido acumulando conocimientos sobre el manejo de ese paisaje (Balée y Erickson 2006, Schaan 2012).

Esta relación hombre-naturaleza debe ser entendida de forma heterárquica (Crumley 2007), esto quiere decir, que el énfasis no está puesto en el poder vertical que va de arriba hacia abajo (aunque no deje de existir), sino en las relaciones horizontales, siempre cambiantes, que se establecen entre los diferentes elementos. Estos no mantienen necesariamente la misma posición. Su papel específico así como la forma en que son entendidos por los otros elementos puede variar dependiendo del contexto. Así, podemos entender esta relación (entre elementos que pertenecen al ámbito social, político, económico, cultural, religioso y simbólico) como una estructura en red con un sinnúmero de conexiones posibles entre ellos (Portocarrero 2010: 21). La síntesis de ese conjunto de relaciones es el paisaje.

El paisaje puede ser estudiado a diversas escalas espacio-temporales. El nivel de detalle dependerá del grado de resolución y de la escala aplicados a la investigación: son las preguntas y los problemas planteados los que las van a determinar (Crumley 1994, 2007). Con un análisis de arqueología del paisaje también se pretende comprender las transformaciones de la relación hombre-naturaleza como el resultado de un proceso histórico, no evolutivo, que puede ser estudiado en su larga, media y corta duración (Balée 1998, 2006; Whitehead 1998, Crumley 2007).

El presente trabajo estuvo centrado en los niveles económico y social, ya que estamos analizando un sistema hidráulico de cultivo, pero enfocándonos en subniveles aún más detallados: la agricultura, la pesca, la caza y los asentamientos; el agua es el eje del sistema, el hilo que construye las redes de interconexión. La escala usada aquí será regional, representando la Sabana de Bogotá su amplitud máxima. En la medida en que sea necesario, su resolución aumentará para ver en detalle alguno de sus elementos como camellones, canales o asentamientos.

Es importante advertir que en el presente trabajo no se entenderá el paisaje de la Sabana como un sistema homeostático, sino como un sistema abierto y dinámico, donde los varios elementos que lo componen están interconectados para garantizar su funcionamiento, y que se encuentra en un proceso continuo de construcción, reconstrucción, abandono y reaprovechamiento. El cambio es un elemento central de la arqueología del paisaje, ya que ni el medio ambiente ni la acción humana son estáticos. Cambios en el clima pueden hacer que el grupo humano reorganice material o mentalmente el paisaje. Así mismo, prácticas como el drenaje de un terreno o el uso intensivo del suelo pueden cambiar las condiciones ambientales existentes, generando de este modo una relación dialéctica de construcción continua del paisaje.

\section{EL AGUA Y EL MEDIO ECOLÓGICO DE LA SABANA DE BOGOTÁ}

El agua fue el eje del sistema de cultivo prehispánico construido en la Sabana, elemento que desde hacía tres millones de años dominaba la planicie, cuando en el proceso final de elevación de la cordillera Oriental, un fenómeno combinado de subsidencia y sedimentación 


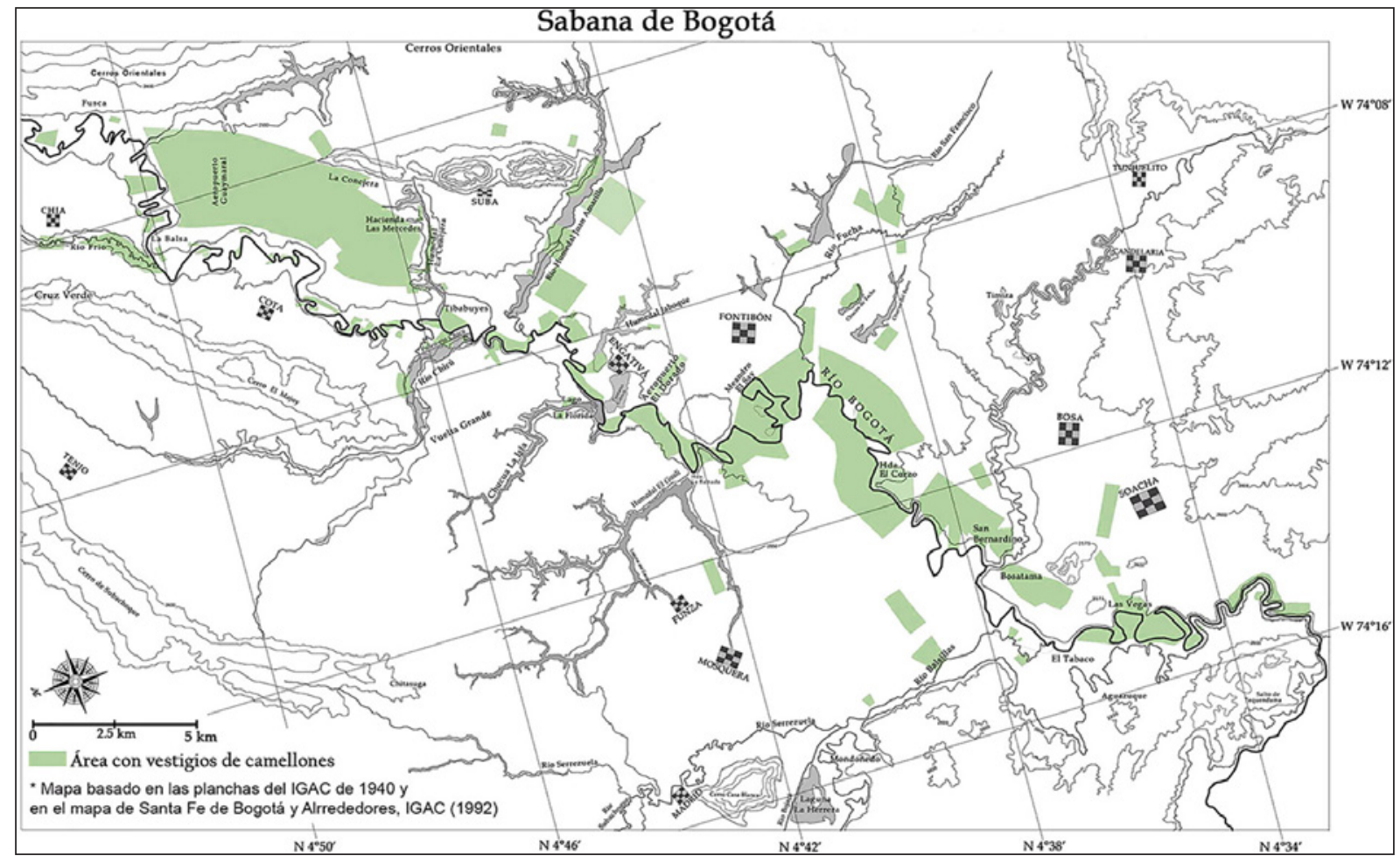

Figura 2. Áreas con camellones identificadas mediante la fotointerpretación.

dio lugar a la formación de un extenso lago, alimentado por los varios afluentes que descendían de las montañas circundantes (Pérez 2000). Hace 30.000 años el nivel del lago comenzó a bajar definitivamente, debido a la erosión y ensanchamiento de la zona de drenaje en Tequendama (como consecuencia de una mayor presión ejercida por el aumento de las masas de agua), seguida de una fase en la que el clima se volvió más seco entre el 32.000 BP y el 27.000 BP (Van der Hammen 1992).

Así, en lo que antes fuera el fondo del lago, se formó una planicie con suelos de origen fluvio-lacustres con abundante presencia de arenas y arcillas, de difícil drenaje, con espejos de agua y con inundaciones periódicas debido al desbordamiento de los ríos que la recorren y que tienen como único valle de drenaje el río Bogotá, que muchas veces no lograba contener en su cauce los grandes volúmenes de agua que recibía (Van der Hammen 1995).

Este valle del río Bogotá atraviesa la Sabana en sentido noreste-suroeste (fig. 2), en un recorrido de $90 \mathrm{~km}$, a lo largo del cual recoge las aguas de varios afluentes (algunos de ellos canalizados hoy en día), entre los que se encuentran el río Frío, Chicú, Juan Amarillo, Fucha, Tunjuelito y Balsillas. También se encuentra circundada por humedales como el de La Conejera, Juan Amarillo,
Jaboque, La Florida, El Gualí y Tibanica, y por la laguna La Herrera, el único lago de dimensiones considerables que aún existe en la Sabana. Posee un leve plano de inclinación en dirección este-oeste, noroeste-centro y suroeste-centro que hacen del sector Funza-Bosa el punto más bajo e inundable, pasando de los $2.600 \mathrm{~m}$ en los cerros orientales a los $2.545 \mathrm{~m}$ en el área central del valle del rio Bogotá (Etayo 2002, Boada 2006).

$\mathrm{Su}$ vegetación nativa de bosque andino presenta especies como Myrcianthes leucoxyla, Duranta mutisii, Vallea stipularis, Ilex kundtiana y Weinmannia tomentosa en los valles interiores de las montañas y en la planicie. En las áreas de inundación estacional hay presencia de bosque de Alnus, y en los humedales, de vegetación abierta de juncos y hierbas pantanosas. Con los procesos de eutrofización que se iniciaron con las prácticas agrícolas, y que se han acentuado en el último siglo, en estos espejos de agua han crecido comunidades flotantes como Limnobium laevigatum y Azolla filiculoide. Por último, encontramos en el suroeste de la Sabana predominio de vegetación xerofítica debido al clima seco que predomina en esta zona (Van der Hammen 1992).

Estas condiciones ecológicas, morfológicas y geográficas, particulares de la Sabana de Bogotá, estimularon diferentes formas de ocupación del espacio por 
los grupos humanos que la habitaron, sin que la presencia del agua fuese un obstáculo insuperable. Por las evidencias arqueológicas sabemos que los cazadoresrecolectores, llegados por primera vez a la Sabana hacia el $12.400 \mathrm{BP}$, se instalaron inicialmente en abrigos rocosos, y después también en campamentos a cielo abierto (Correal et al. 1969, Correal y Van der Hammen 1977, Groot 1992, Pinto 2003). Los grupos hortícolas parecen haber abandonado definitivamente los abrigos, concentrándose en los asentamientos a cielo abierto, y finalmente los grupos agrícolas habrían colonizado los diversos entornos: terrazas aluviales, las faldas de las montañas, los valles inter-fluviales y los valles de inundación.

\section{LOS AGRICULTORES DE LA SABANA}

Hace 5.000 años los primeros horticultores de la Sabana se instalaron definitivamente en campamentos a cielo abierto, en terrazas naturales o artificiales, donde desarrollaron actividades como la caza, la recolección, la pesca y una incipiente agricultura. Alrededor de la laguna de La Herrera (Broadbent 1971, Rodríguez Cuenca y Cifuentes 2005), en Aguazuque (Correal 1990), Zipacón (Correal y Pinto 1983), Tocarema (Peña 1988), Tequendama (Correal y Van der Hammen 1977), Chía (Ardila 1984), y Zipaquirá (Cardale 1981) se encontraron varios asentamientos cuyos vestigios evidenciaron la introducción de nuevas prácticas, como el procesamiento de alimentos y la elaboración de cerámica.

La tradición arqueológica ha dividido los grupos agroalfareros del altiplano Cundiboyacense en Herrera, Muisca Temprano y Muisca Tardío. Sin embargo, las evidencias arqueológicas y bioantropológicas (Rodríguez Cuenca 2011) han mostrado que existe una homogeneidad intrarregional entre los grupos del altiplano, producto de la ausencia de fuertes flujos migratorios posteriores a su primer arribo, lo que quiere decir que estamos frente a un grupo que por casi 12.000 años habitó el altiplano, transformándose, complejizando sus estructuras sociales y políticas, hasta formar la sociedad de cacicazgos que los españoles encontraron en 1536 (tabla 1).

Esta interacción de larga duración entre los habitantes del altiplano y su medio ecológico permite comprender por qué fue posible la transformación de la Sabana de Bogotá en una próspera planicie cubierta de canales, plataformas para el cultivo y una alta densidad de asentamientos. Para facilitar la discusión vamos a mantener esta división: Herrera: 800 a.C. - 100 d.C.; Muisca Temprano: 100 d.C. - 1000 d.C.; Muisca Tardío: 1000 d.C. - 1550 d.C., pero sin perder de vista que se trata de los procesos de transformación del mismo grupo humano a lo largo del tiempo (el debate sobre la cronología de la Sabana de Bogotá y sobre las razones del uso de la presente cronología se pueden consultar en Rodríguez Gallo 2015: cap. 2.3).

Durante el Herrera tenemos una progresiva sedentarización, con asentamientos dispersos en la Sabana, preferentemente en terrazas fuera del alcance de las inundaciones pero con acceso directo al agua (Kruschek 2003, Romano 2003, Boada 2006). Esta elección debió estar influenciada por la calidad de los suelos que predominan en esta región, andisols con alto contenido de ceniza volcánica y materia orgánica, muy adecuados para el cultivo (Van der Hammen 2003). Durante el Herrera también se encuentran las primeras evidencias de cultivo de maíz en el altiplano: El Abra: 800 a.C. (Correal et al. 1969); Laguna de La Herrera: 740 a.C. (Van der Hammen 2003); y La Filomena: 738 a.C. (Boada 2006).

Durante el Muisca Temprano la densidad poblacional registra un fuerte aumento, con asentamientos dispersos y aldeas nucleadas. Los lugares ya habitados se mantienen, extendiéndose hacia las áreas vecinas, incluyendo las terrazas a lo largo del río Bogotá y el valle aluvial (Boada 2006: 73). Un elemento interesante de este periodo es que por primera vez el valle del río Tunjuelito, al sur de Bogotá, es colonizado por los habitantes de la Sabana. La fecha más antigua para esta región es de 770 d.C., proveniente del barrio Las Delicias (Enciso 1990). Sin embargo, rápidamente los asentamientos se multiplican y expanden, como se puede constatar a través de las evidencias arqueológicas (Boada 2000a, Bonilla 2005, 2008; Langebaek 2011). Es probable que el clima, predominantemente seco, y la geología de la zona hubiesen influido en el tardío poblamiento del sur de la Sabana. Sus suelos pertenecen en gran medida a la Formación Tunjuelito, caracterizada por la presencia de arcillas, gravas y cantos de grandes dimensiones que los hacen muy compactos y de difícil manejo para las labores agrícolas (Rodríguez Gallo 2011).

Para el Muisca Tardío hubo una complejización de las estructuras sociales, que llevaron a la organización de cacicazgos confederados (Gamboa 2008), donde la diferenciación social no estuvo basada en la riqueza sino en el prestigio personal (Boada 2000a, 2006; Kruschek 2003). La organización mixta del espacio se consolidó, con aldeas nucleadas (cercados) y asentamientos dispersos. Además, hubo un evidente aumento 
Tabla 1. Dataciones de $\mathrm{C}^{14}$ para la Sabana de Bogotá.

\begin{tabular}{|c|c|c|c|c|c|}
\hline No. Laboratorio & Fecha C14 BP & $\begin{array}{l}\text { Fecha calibrada } \\
\text { C14 BP(sigma 2) }\end{array}$ & $\begin{array}{c}\text { Fecha C14 } \\
\text { AC / DC }\end{array}$ & Sitio & Fuente \\
\hline GrN 5556, Col 85 & $12400 \pm 160$ & $14626 \pm 414$ & $12676 \pm 414 \mathrm{AC}$ & Abra & Correal et al., 1969 \\
\hline GrN 6505 & $10590 \pm 260$ & $12365 \pm 361$ & $10415 \pm 361 \mathrm{AC}$ & Tequendama & $\begin{array}{l}\text { Correal y Van der } \\
\text { Hammen, } 1977\end{array}$ \\
\hline GrN 6732 & $10130 \pm 150$ & $11768 \pm 312$ & $9818 \pm 312 \mathrm{AC}$ & Tequendama & $\begin{array}{l}\text { Correal y Van der } \\
\text { Hammen, } 1977\end{array}$ \\
\hline GrN 5561, Col 83 & $9340 \pm 90$ & $10543 \pm 127$ & $8593 \pm 127 \mathrm{AC}$ & Abra & Correal et al., 1969 \\
\hline GrN 16346 & $8740 \pm 60$ & $9746 \pm 118$ & $7796 \pm 118 \mathrm{AC}$ & Galindo & Pinto, 2003 \\
\hline GrN5710, Col 82 & $8670 \pm 400$ & $9725 \pm 496$ & $7775 \pm 496 \mathrm{AC}$ & Abra & Correal et al., 1969 \\
\hline Beta 53925 & $8200 \pm 110$ & $9188 \pm 146$ & $7238 \pm 146 \mathrm{AC}$ & Checua & Groot, 1992 \\
\hline Beta 53924 & $7800 \pm 160$ & $8683 \pm 212$ & $6733 \pm 212 \mathrm{AC}$ & Checua & Groot, 1992 \\
\hline $\begin{array}{c}\text { GrN 14477, Col } \\
1592\end{array}$ & $5025 \pm 40$ & $5790 \pm 76$ & $3840 \pm 76 \mathrm{AC}$ & Aguazuque & Correal, 1990 \\
\hline $\begin{array}{c}\text { GrN 12930, Col } \\
477\end{array}$ & $4030 \pm 35$ & $4502 \pm 48$ & $2552 \pm 48 \mathrm{AC}$ & Aguazuque & Correal, 1990 \\
\hline $\begin{array}{c}\text { GrN 14478, Col } \\
593\end{array}$ & $3850 \pm 35$ & $4283 \pm 82$ & $2333 \pm 82 \mathrm{AC}$ & Aguazuque & Correal, 1990 \\
\hline GrN-11125 & $3270 \pm 30$ & $3507 \pm 42$ & $1557 \pm 42 \mathrm{AC}$ & Zipacón & $\begin{array}{c}\text { Correal y Pinto, } \\
1983\end{array}$ \\
\hline $\begin{array}{c}\text { GrN } 12929, \mathrm{Col} \\
476\end{array}$ & $3140 \pm 35$ & $3375 \pm 30$ & $1425 \pm 30 \mathrm{AC}$ & Vistahermosa & Correal, 1987 \\
\hline $\begin{array}{c}\text { GrN 12928, Col } \\
475\end{array}$ & $3135 \pm 35$ & $3366 \pm 32$ & $1416 \pm 32 \mathrm{AC}$ & Vistahermosa & Correal, 1987 \\
\hline GX - 30239 & $3050 \pm 40$ & $3276 \pm 54$ & $1326 \pm 54 \mathrm{AC}$ & Guaymaral & Boada, 2006 \\
\hline Beta 20951 & $2750 \pm 100$ & $2897 \pm 108$ & $947 \pm 108 \mathrm{AC}$ & Tocarema & Peña, 1991 \\
\hline GX - 30234 & $2450 \pm 40$ & $2538 \pm 125$ & $588 \pm 125 \mathrm{AC}$ & La Filomena & Boada, 2006 \\
\hline GrN-6536 & $2225 \pm 65$ & $2234 \pm 76$ & $284 \pm 76 \mathrm{AC}$ & Tequendama & $\begin{array}{l}\text { Correal y Van der } \\
\text { Hammen, } 1977\end{array}$ \\
\hline GrN 6544 & $2210 \pm 65$ & $2223 \pm 80$ & $273 \pm 80 \mathrm{AC}$ & Nemocón & Cardale, 1981 \\
\hline GrN 8452 & $2100 \pm 60$ & $2088 \pm 80$ & $138 \pm 80 \mathrm{AC}$ & Zipaquirá & Cardale, 1981 \\
\hline GrN 6542 & $1975 \pm 60$ & $1935 \pm 63$ & $15 \pm 63 \mathrm{DC}$ & Nemocón & Cardale, 1981 \\
\hline GrN 8453 & $1955 \pm 40$ & $36 \pm 44$ & $36 \pm 44 \mathrm{DC}$ & Zipaquirá & Cardale, 1981 \\
\hline GrN 8454 & $1920 \pm 35$ & $1873 \pm 37$ & $77 \pm 37 \mathrm{DC}$ & Zipaquirá & Cardale, 1981 \\
\hline GrN 9240 & $1890 \pm 50$ & $1825 \pm 62$ & $125 \pm 62 \mathrm{DC}$ & Zipaquirá & Cardale, 1981 \\
\hline GrN 15742 & $1820 \pm 80$ & $1746 \pm 99$ & $204 \pm 99$ DC & Tocarema & Peña, 1991 \\
\hline$G X-30235$ & $1510 \pm 40$ & $1419 \pm 59$ & $531 \pm 59 \mathrm{DC}$ & La Filomena & Boada, 2006 \\
\hline GX - 30238 & $1370 \pm 40$ & $1300 \pm 22$ & $650 \pm 22 \mathrm{DC}$ & Guaymaral & Boada, 2006 \\
\hline Beta 176592 & $1230 \pm 70$ & $1160 \pm 82$ & $790 \pm 82 \mathrm{DC}$ & San Carlos & Romano, 2003 \\
\hline Beta 176594 & $1190 \pm 40$ & $1121 \pm 51$ & $829 \pm 51 \mathrm{DC}$ & San Carlos & Romano, 2003 \\
\hline Beta 176593 & $1010 \pm 60$ & $910 \pm 71$ & $1040 \pm 71 \mathrm{DC}$ & San Carlos & Romano, 2003 \\
\hline
\end{tabular}


poblacional que llevó a la densificación en la ocupación de espacio (Boada 2000b, 2006; Kruschek 2003). Los asentamientos en las zonas bajas de la planicie, como la llanura de Funza, continuaron aumentando, así como aquellos localizados en las faldas de los cerros de Cota y Suba y en la llanura de inundación del río Bogotá.

Este espectacular aumento de la población, que se registra desde el Herrera hasta el Muisca Tardío, no habría sido posible sin el desarrollo de formas eficientes de producción agrícola y sin un sistema de manejo del agua que permitiese ocupar zonas de fácil inundación, ganándole progresivamente tierra firme al agua. El sistema hidráulico se comenzó a construir hace 3.000 años, según las dataciones disponibles hasta el momento para la Sabana de Bogotá: las fechas más antiguas para los camellones de la Sabana son de $1324 \pm 40$ a.C. en Guaymaral y $738 \pm 40$ a.C. en La Filomena (Boada 2006), que coinciden con las dataciones de las primeras evidencias de polen de maíz: $1320 \pm 39$ a.C. en el sitio Zipacón (Correal y Pinto 1983), y $740 \pm 100$ a.C. en el sitio La Herrera (Van der Hammen 2003), y con su presencia en la dieta: valores de C13 de -14,4 y -14,7 en individuos del sitio Tequendama para el intervalo 1500 a.C. -1000 a.C., que muestran que su consumo comienza a ser regular, y de $-10,4$ y $-11,2$ en huesos de Aguazuque datados en 775 a.C., que evidencian una decidida dependencia del maíz (Correal et al. 1990).

La construcción del sistema hidráulico pudo tener inicio en el aprovechamiento de las barras de sedimentación, que la migración de los meandros del río Bogotá iba dejando, como plataformas para el cultivo (Broadbent 1968, Bernal 1990). Luego se fue expandiendo progresivamente hasta abarcar buena parte de la Sabana de Bogotá, ayudado en parte por el clima seco que se registró entre 700 a.C. y 61 a.C. (Van der Hammen 2003, Berrio 2006).

\section{LOS CAMELLONES Y LA CONSTRUCCIÓN DEL PAISAJE EN LA SABANA}

\subsection{Las estructuras en tierra en el contexto latinoamericano}

Las prácticas agrícolas han transformado profundamente el espacio que habitamos (sin excluir que la actividad de recolección también lo hizo (Schaan 2012, Smith 2014)), creando paisajes completamente antropizados en los que los bosques han cedido su lugar a espacios abiertos, donde las plantas escogidas han crecido y dado sus frutos en abundancia. La quema es una de las formas más simples para obtener un terreno limpio y preparado para el cultivo. Sin embargo, a lo largo de la historia se han generado diversas formas de explotación y aprovechamiento de los suelos según las condiciones del terreno, el clima o las necesidades humanas. Existen sistemas especializados de agricultura como las terrazas, los sistemas de irrigación y los sistemas de drenaje; estos últimos, típicos de áreas inundables, como es el caso de la Sabana de Bogotá.

El manejo del agua, a través de la construcción de infraestructuras y del desarrollo de técnicas específicas como la irrigación o el drenaje, fue un elemento central en la organización de varios grupos prehispánicos en diversas áreas del continente americano: desde las tierras altas del Vale de México hasta el Lago Titicaca en la zona andina de Perú y Bolivia, pasando por las Antillas hasta las tierras bajas de Colombia y de la región amazónica boliviana y de Venezuela, podemos hoy encontrar vestigios arqueológicos de formas de agricultura basadas en sistemas de drenaje. Sin embargo, salvo el caso de México, donde el sistema de chinampas se conoce desde el período colonial, sin haber perdido su vigencia, estos sistemas agrícolas cayeron en el olvido, siendo redescubiertos apenas en el siglo XX (Denevan 1970).

Entre los varios trabajos que desde entonces se han desarrollado sobre los sistemas de drenaje se pueden mencionar las investigaciones de Denevan et al. (1968), Erickson (1988, 1993), Graffam (1990) y Bandy (2005) para la región del Lago Titicaca; Parsons (1970), Delgado-Espinoza (2002) y Cadudal (2007) para Guayas y La Tolita en el Ecuador; Plafker (1964) para el Llano de Mojos al norte de Bolivia; Hammond (1984) y Siemens (1983) para la región de Mesoamérica; Sturtevant (1961) para las Antillas; Gassón (1998) para Barinas, Venezuela; y Parsons y Bowen (1966), Plazas y Falchetti (1986) y Plazas et al. (1988, 1993) para la Depresión Momposina, en el norte de Colombia.

La interpretación inicial sobre estos sistemas de drenaje es que debían ser, tal como los sistemas de irrigación, producto de sociedades con un gobierno burocrático centralizado, que pudiera planear y coordinar tanto la construcción de la infraestructura como las labores de mantenimiento y las actividades agrícolas posteriores (Wittfogel (1957), según Erickson 1993: 371). Sin embargo, los estudios llevados a cabo a partir de finales de los años 60 comenzaron a mostrar, en primer lugar, que estas formas de producción agrícola eran anteriores al desarrollo de Estados centralizados (Denevan et al. 1968, Erickson 1993) y, en segundo lugar, que no respondían necesariamente a situaciones de 
presión por escasez de alimentos (Erickson 1993). El caso de la Sabana de Bogotá correspondería a una situación similar, ya que estos trabajos en tierra comenzaron a ser construidos por sociedades que estaban apenas caminando hacia la formación de cacicazgos, y que para el momento de la colonización española estaban en proceso de consolidación de confederaciones de cacicazgos.

A partir de los experimentos realizados por Erickson en el lago Titicaca, sobre construcción y productividad de los camellones, (se usó arado de pie tradicional para la construcción experimental), se demostró que tres personas (dos removiendo la tierra del área del canal y otra distribuyéndola para formar la plataforma elevada), lograron remover $3 \mathrm{~m}^{3}$ de tierra en una hora, lo que quiere decir que cada persona lograría remover $5 \mathrm{~m}^{3}$ de tierra en un día de trabajo de cinco horas. Este resultado fue similar al obtenido en otros cuatro casos: en Candile, Viscachani, Machachi y Jucchata las personas removieron $5,13 \mathrm{~m}^{3}$ de tierra en un día de trabajo de cinco horas. Si suponemos que las familias nucleares estaban integradas en promedio por cinco individuos adultos, cada familia podría construir una hectárea de camellón (canal y plataforma) de $20 \mathrm{~cm}$ de altura, en 40 días, y un grupo de 200 personas lograrían construir esta misma extensión de terreno en un día, como sucedió en Candile. En Viscachani, un grupo de 167 personas lograron construir una hectárea por día. Estos resultados, ligeramente mejores que los de Candile, se deberían a la excelente organización de la comunidad para ejecutar la obra (Erickson 1988: 221-225). Estos y otros experimentos llevaron a Erickson a proponer que una persona podría subsistir sembrando $540 \mathrm{~m}^{2}$ de camellones al año, y una familia de cinco individuos sembrando $2.660 \mathrm{~m}^{2}$.

La reconstrucción experimental que se desarrolló en el lago Titicaca también permitió obtener datos aproximados sobre los niveles de productividad de estas formas de cultivo tradicionales, lo que demuestra que efectivamente tenían la capacidad de mantener una población en crecimiento, como sucedió en la Sabana de Bogotá. Esto no quiere decir que el sistema hidráulico de cultivo fuera necesariamente construido con el objetivo de generar excedentes o de responder a una situación de presión poblacional, pero lo que se puede constatar es que estaba en la capacidad de garantizar una producción de alimentos sin temor a hambrunas, al mismo tiempo que permitía sostener el crecimiento poblacional (Rodríguez Gallo 2011), que para el caso de la Sabana de Bogotá fue permanente: el registro regional sistemático desarrollado por Boada (2006) mostró que la densidad poblacional aumentó de forma constante desde las primeras sociedades agrícolas (los Herrera) hasta la consolidación de los cacicazgos muiscas.

Este tipo de investigaciones experimentales muestra la viabilidad que tuvieron los camellones como forma de explotación productiva, a partir del trabajo comunitario, pero no se puede olvidar que cada región del continente tuvo sus propias especificidades, tanto en relación con las condiciones geográficas y ecológicas del lugar, como con la organización social de los grupos.

\subsection{El sistema hidráulico de campos elevados de cultivo en la Sabana de Bogotá}

Las prácticas agrícolas de los Muiscas fueron un asunto que poco interesó a los cronistas de la colonia. Apenas tenemos una referencia concreta al sistema de camellones, hecha por Fray Pedro de Aguado, quien afirmó que el maíz entregado como tributo por los Muiscas no era cultivado de forma tradicional sino en «cierta manera de camellones altos que hacen a mano» (Aguado 1957 [1582] v 4: 143). Después el silencio se instaló y solo volvemos a oír hablar de esa ya «antigua forma de cultivo» en el siglo XIX, por boca de Humboldt y Acosta, pero también en este caso mediante breves referencias (Broadbent 1968). Su estudio solo se inició con Sylvia Broadbent en los años 60, quien llamó la atención sobre el valor de las fotografías aéreas de las décadas precedentes para el estudio del sistema agrícola prehispánico.

Ella identificó por primera vez los camellones que se encuentran entre Suba y Guaymaral, a través de la fotointerpretación (1968), y llevó a cabo trabajos de reconocimiento en campo y de excavación que le permitieron verificar la técnica de construcción: plataformas elevadas para el cultivo y canales para controlar el exceso de humedad por alto nivel freático (1987). Bernal (1990) realizó un trabajo similar de fotointerpretación y de excavación en el valle del río Bogotá, en el sector La Ramada, Funza, corroborando los resultados presentados por Broadbent.

Al final de la década de 1990, Ana María Boada realizó un registro regional sistemático del área central y norte de la Sabana de Bogotá que incluyó la reconstrucción digital y el análisis morfológico e hidráulico del sistema. A partir de ese trabajo se corroboró que toda la planicie había sido habitada y cultivada, lo que constituyó un avance importante en la forma de comprender su proceso de ocupación, ya que aún a mediados del siglo XX investigadores como Haury y Cubillos 
sostenían que el poblamiento de la Sabana de Bogotá debió ser inviable durante el periodo prehispánico debido al carácter inundable de la planicie. Haury y $\mathrm{Cu}-$ billos (1953) sostuvieron que no era posible imaginar un sistema agrícola prehispánico allí, salvo excepciones puntuales como la de los asentamientos identificados en Chía, Funza y Fontibón. En general, se debía hablar de una agricultura de ladera que debió aprovechar las pequeñas serranías que abundan en la Sabana de Bogotá.

Durante su investigación, Boada identificó 15.751 ha con vestigios del sistema hidráulico y realizó excavaciones en Guaymaral y el cerro de Suba (sector La Filomena), que permitieron la obtención de las primeras dataciones de las estructuras en tierra (Boada 2000b, 2006). Por los mismos años Miguel Etayo (2002) realizó un análisis geológico del río Bogotá, mostrando que la morfología de los camellones estaba directamente relacionada con el plano de inclinación de la llanura y con el volumen de agua del río. Más tarde estos trabajos fueron complementados por el análisis del sector sur de la Sabana, realizado por Rodríguez Gallo (2011). En él se hizo la reconstrucción por fotointerpretación del sistema hidráulico en el valle del rio Tunjuelito y se constató un cambio en el curso del río Bogotá, que estaría mostrando dos momentos cronológicos diferentes en la construcción de los camellones en el sector Bosatama-San Bernardino.

Estas investigaciones centraron su trabajo en la reconstrucción del sistema y en su análisis morfológico e hidráulico. El trabajo de Boada (2006) en particular procuró establecer una relación entre este y los patrones de asentamiento de los grupos prehispánicos. En el presente artículo se pretende discutir el sistema hidráulico desde una perspectiva más amplia, enfocada en la relación hombre-medio ecológico, en particular en la relación de los grupos prehispánicos (Muiscas del periodo Tardío) con el agua, para explicar cómo se integraron agua, cultivos, pesca, caza y zonas de habitación, en síntesis, cómo fue construido el paisaje prehispánico de la Sabana de Bogotá.

Los camellones son un sistema de drenaje construido con el objetivo de controlar los excesos de agua presente en planicies inundables. Está constituido por plataformas elevadas para el cultivo, que mantenían secas las raíces de las plantas, separadas por canales para el drenaje del agua (Broadbent 1968, Bernal 1990, Boada 2006). Estos canales requerían de una limpieza periódica, para retirar el material orgánico que se acumulaba después del periodo de lluvias. Los limos retirados de los canales eran depositados sobre las plataformas, lo que constituía una fuente de nutrientes permanente para las sementeras, garantizando una productividad superior a la de los cultivos tradicionales.

Tenía la ventaja adicional de neutralizar los efectos adversos de las heladas, típicas de las tierras andinas: el agua de los canales se calentaba durante el día y por la noche su calor mantenía tibia la tierra, evitando que las bajas temperaturas quemasen los cultivos. El tamaño y morfología de los canales y de las plataformas variaba según el grado de inclinación de la planicie, el volumen de agua a controlar, las características del suelo o de la propia forma del río. Habrían sido construidos por núcleos familiares o por pequeños grupos comunitarios, sin que fuera necesario un poder central que organizase el trabajo (Erickson 1988).

En la Sabana de Bogotá estas estructuras en tierra se comenzaron a construir hace alrededor de 3.000 años, y estaban activas para el momento de la colonización (la datación más tardía para el sistema de camellones es de $1767 \pm 40$ d.C. (Boada 2006)). Se extendió por la actual ciudad de Bogotá y por los municipios de Chía, Cota, Funza, Mosquera, Soacha y Sibaté, con el río Bogotá como su eje central. En términos morfológicos identificamos seis tipos de estructuras: canales lineales, camellones ajedrezados, en fila, en cuadrícula, paralelos e irregulares (fig. 3). Los canales irradian de la línea de agua y su función principal es drenar rápidamente los excesos de agua hacia el interior de la planicie, para evitar desbordamientos descontrolados. Predominan en el área central de la Sabana, pudiendo alcanzar longitudes de $2 \mathrm{~km}$ con un ancho de $12 \mathrm{~m}$ (sector San Bernardino), separados por plataformas de $4 \mathrm{~m}$ a $7 \mathrm{~m}$.

Los camellones ajedrezados (ver fig. 3a) son conjuntos de pequeñas plataformas separadas por canales (3 a 10 plataformas por grupo). Se localizan en la planicie, por encima de la llanura aluvial, y su objetivo es contrarrestar los encharcamientos producidos por alto nivel freático, por lo cual no necesitan de grandes canales para drenaje. Se encuentran elevados a $50-70 \mathrm{~cm}$ del suelo, tienen $20 \mathrm{~m}-50 \mathrm{~m}$ de largo por $2 \mathrm{~m}-5 \mathrm{~m}$ de ancho, con canales de $50 \mathrm{~cm}$ a $2 \mathrm{~m}$ de ancho (Broadbent 1968, Bernal 1990, Boada 2006).

En el norte de la Sabana fueron identificados camellones en fila, localizados en contextos geomorfológicos similares a los de los ajedrezados, por lo que se deduce que estarían destinados a controlar el alto nivel freático. Se trata de pequeñas plataformas dispuestas una detrás de la otra, sin grandes canales alrededor, pero, dado que solo se identificaron pequeños sectores, 


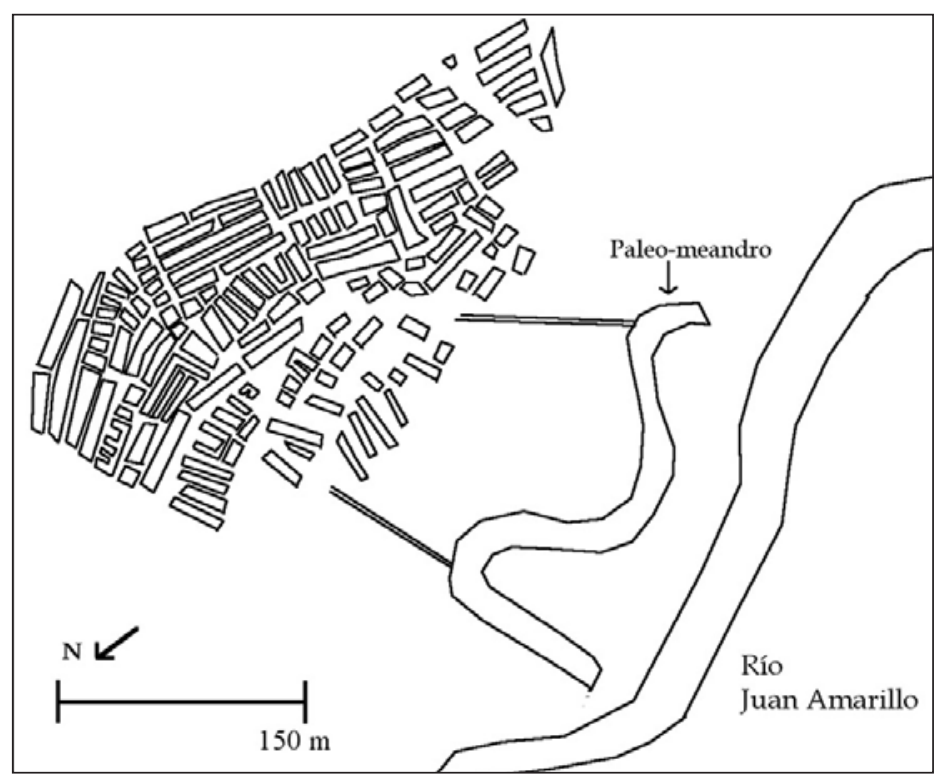

Figura 3a. Camellones ajedrezados. Río Juan Amarillo. Límite entre el sector norte y centro de la Sabana de Bogotá.

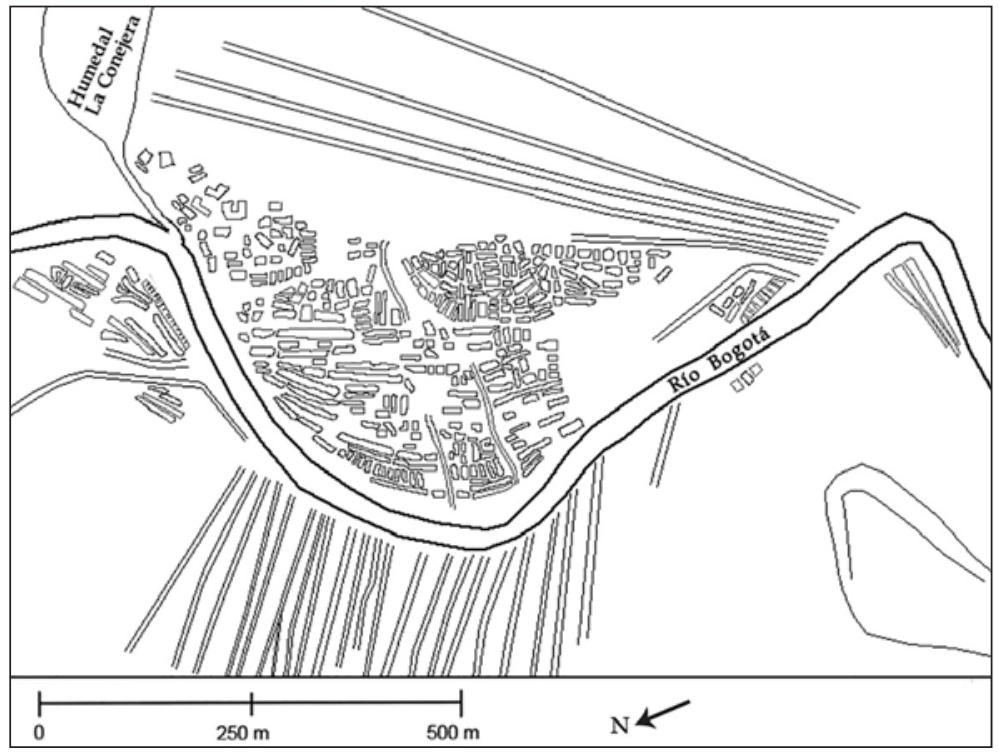

Figura 3b. Camellones lineales, paralelos e irregulares. Río Bogotá. Sector norte de la Sabana de Bogotá.

Figura 3.

Ejemplos de la morfología de los camellones. su interpretación se dificulta. No descartamos que se trate en realidad de restos de camellones ajedrezados, de los cuales tendríamos apenas una visión parcial.

Este también puede ser el caso de los camellones en cuadrícula, identificados en Bosa y Soacha. En las aerofotografías son visibles plataformas cuadradas o rectangulares que parecen estar formando una cuadrícula, pero es posible que cada una represente un conjunto de camellones ajedrezados cuyos canales de separación se fueron sedimentando hasta formar una 


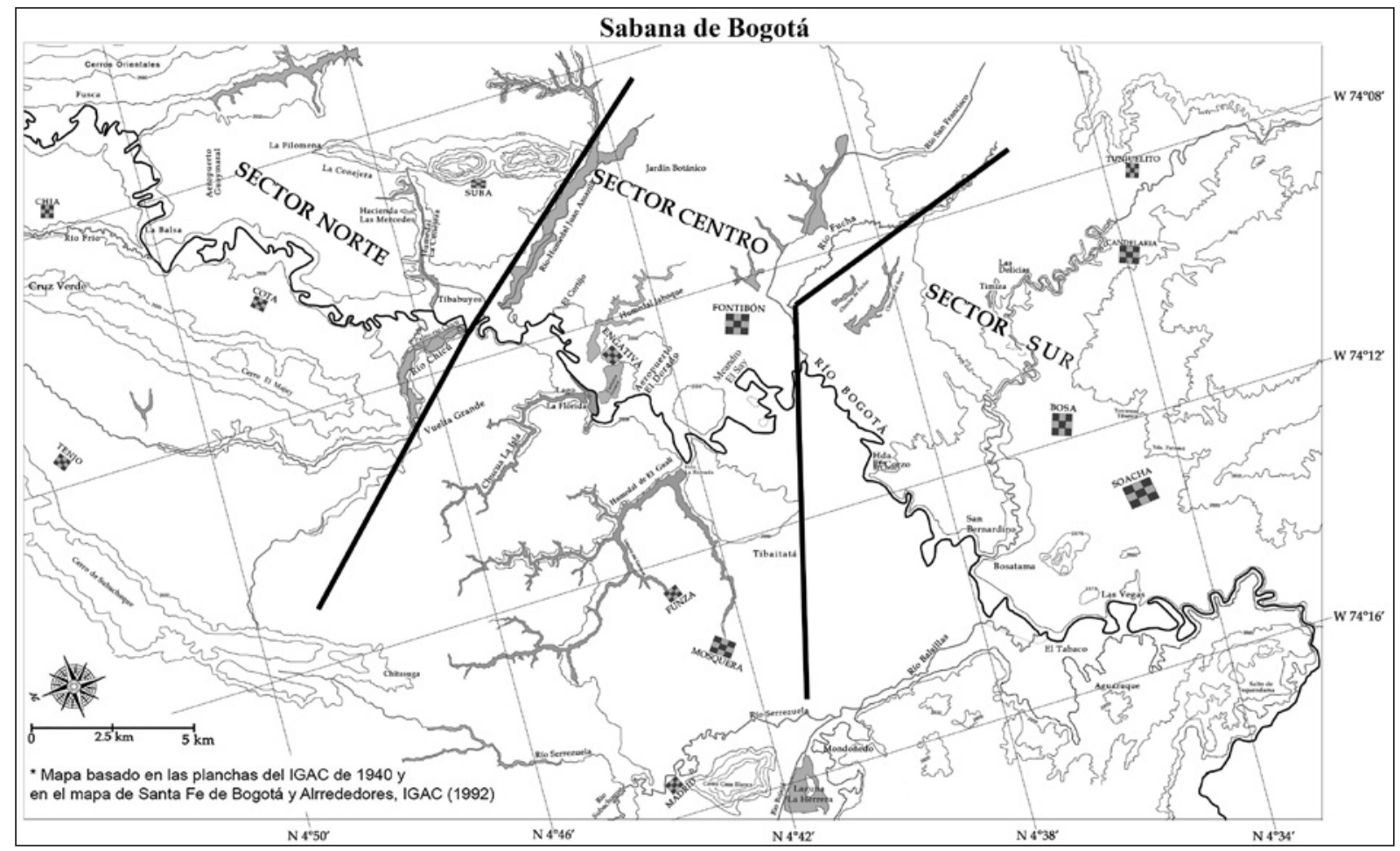

Figura 4. División del área de estudio.

única plataforma. También se encuentran localizados fuera del área de influencia de las inundaciones y no poseen canales de drenaje que conecten con el río.

Los camellones paralelos al río se construyeron aprovechando las barras de sedimentación dejadas por la migración de los meandros. Sus dimensiones varían según el tamaño de la longitud de onda del meandro. Es posible que algunos canales lineales actuaran como sistemas de protección de los camellones paralelos, dada su ubicación en la llanura de inundación, como se ilustra en la figura 3b. Los camellones irregulares también se encuentran generalmente a lo largo del río Bogotá, en la llanura de inundación. No poseen un tamaño ni un patrón morfológico definido. Pueden estar aislados u organizados en pequeños grupos, sin que sean observables canales definidos. Sus formas son variadas: circulares, ovaladas, cuadradas, rectangulares o trapezoidales. Desde nuestro punto de vista este aparente caos deriva de la destrucción parcial del sistema hidráulico posterior a la colonización, y no de una situación morfológica original: la planicie aluvial ha estado expuesta a inundaciones periódicas, cuyos sedimentos fueron rellenando los antiguos canales, destruyendo su trazado inicial y las formas originales de las plataformas.

\section{DISCUSIÓN: EL SISTEMA HIDRÁULICO Y SU RELACIÓN CON LA SABANA Y CON LOS ASENTAMIENTOS}

Para facilitar el análisis del sistema hidráulico, éste será dividido en tres unidades diagnósticas (fig. 4), siguiendo límites naturales específicos, pero también buscando integrar un conjunto de rasgos que diferencian un sector del otro, como vamos a ver a continuación.

\subsection{Sector Norte}

Para iniciar el análisis del sistema hidráulico, debemos tener en cuenta que aquello que hoy vemos en las aerofotografías es una imagen de los camellones en el momento de su abandono, en el siglo XVI, pero además, transformada por casi medio milenio de modificaciones constantes del paisaje (de mediados del siglo XVI a mediados del siglo XX, cuando las fotografías aéreas fueron tomadas) que incluyen trabajos de drenaje, agrícolas, crecimiento urbano y modificación de la biota original. Hacemos este llamado de atención porque algunas veces el sistema hidráulico ha sido interpretado 
a partir de lo visto en la fotografía, sin aplicar los filtros necesarios (ver Broadbent 1968, Boada 2006). Es preciso evaluar si un área actual de humedal ya existía en el periodo prehispánico o si la ausencia de vestigios de camellones en las aerofotografías correspondería a la situación original o no, por ejemplo. En este sentido hay que tener en cuenta que con el sistema hidráulico funcionando, las áreas de inundación permanente deberían ser mucho menores que después del abandono del sistema, lo que nos llevaría a deducir que muchos de los actuales humedales no existían en la última fase del periodo prehispánico.

También es necesario advertir que un sistema de manejo de agua como el sistema hidráulico tiende a generar la inmovilidad de los cursos de agua que forman parte de él, al controlar los desbordamientos (Etayo 2002), por lo cual, la sinuosidad del río puede no ser producto de sus dinámicas internas, sino de factores externos: los canales distribuyen los excesos de agua controlando su energía, minimizando así las posibilidades de cambio de los cursos de los meandros. En consecuencia, examinar la movilidad del río nos ayuda a evaluar la influencia que tuvo el sistema hidráulico en el recorrido del río.

En el tramo del río localizado en el Sector Norte observamos procesos de crecimiento y posterior truncamiento de meandros, pero no de migración progresiva o de cambios en el curso del río. Hay pocos paleo-meandros, la mayor parte de ellos activos durante el Muisca Tardío, lo que se deduce del hecho de que estos paleomeandros tienen camellones que se articulan sin interrupción con los camellones de los meandros activos.

Lo más relevante de este sector es la gran densidad de estructuras del tipo ajedrezado. Cubren aproximadamente $32 \mathrm{~km}^{2}$ en la planicie de Guaymaral-Las Mercedes y se encuentran algunos grupos aislados entre los humedales La Conejera y Juan Amarillo, detrás del cerro de Suba y en la banda norte del río Chicú (fig. 2). También a lo largo de la planicie aluvial del río Frío, en Chía, son visibles aún camellones ajedrezados y en fila, y junto a los cerros Orientales a la altura de Fusca. Si tenemos en cuenta que esta región norte está dominada por andisols de alta calidad para el cultivo, que está formada en buena medida por terrazas por encima del nivel del río y que presenta encharcamientos por alto nivel freático, comprendemos por qué esta es la morfología predominante en la zona. También nos permite deducir que las planicies de Cota, Chía, Suba y entre el cerro de Suba y los cerros Orientales, estaban cubiertas por este tipo de cultivos. A este respecto, un documento colonial describe las sementeras que había en Cota para
1594, en el que es evidente que los indígenas mantenían toda esta planicie cultivada con maíz y tubérculos. Se menciona que había labranzas a todo lo largo de la planicie que está entre el río Bogotá y el cerro Majuy (Indios de Cota... Escribanía de Cámara, 840A).

Se observan pocos canales para drenaje. Los existentes están concentrados en los meandros de Tibabuyes-Chicú, donde alcanzan extensiones de $600 \mathrm{~m}$ de largo x $6-8 \mathrm{~m}$ de ancho, lo que indica que esta era una zona crítica para los desbordamientos. De hecho, en este punto el valle de inundación se amplía. Los excesos de agua debían ser direccionados hacia el interior de la planicie o concentrados en puntos específicos de la vega del río, en sectores que hemos llamado de mitigación, es decir, sectores específicos de la Sabana que eran inundados de forma intencional en los periodos de mayor pluviosidad o de crecientes de los ríos, resguardando de esta forma las áreas de cultivo, de habitación o los caminos. Estas áreas de mitigación fueron definidas teniendo en cuenta la geomorfología del área donde se ubicarían, la ausencia de cualquier vestigio del sistema hidráulico, la ausencia de material arqueológico que indicase presencia de actividad humana y las descripciones de la documentación colonial sobre la Sabana de Bogotá. En el sector norte encontramos tres puntos que podrían corresponder a áreas de mitigación: en el meandro de Pueblo Viejo (Cota), en Tibabuyes (ya descrita como una laguna por los primeros conquistadores (Velandia 1979 v 2: 822)) y en la banda norte del paleo-río Chicú, sector La Culebrera.

Los humedales La Conejera y Juan Amarillo eran originalmente valles erosivos. El área a su alrededor se encharcaba, pero esta situación estaba controlada por los camellones ajedrezados: en las fotografías aéreas son visibles camellones que se internan en el agua, mostrando que el anegamiento permanente que se registra actualmente es posterior a la desactivación del sistema hidráulico. En el caso de Juan Amarillo actualmente tenemos un sistema mixto de lago, humedal, y un pequeño tramo del valle erosivo original en la confluencia con el río Bogotá.

El río Chicú también ha sufrido fuertes modificaciones. En la aerofotografía podemos observar que a la altura de la punta sur del cerro Majuy, un paleo-curso se bifurca a la izquierda del actual valle de erosión, perdiéndose en medio del humedal para reaparecer desembocando en un paleo-meandro del río Bogotá, que se localizaba en el mismo punto donde está la desembocadura actual (fig. 5). Este debía ser el curso original del río Chicú. No sabemos en qué momento cambió, pero el suceso puede estar relacionado con las inundaciones 


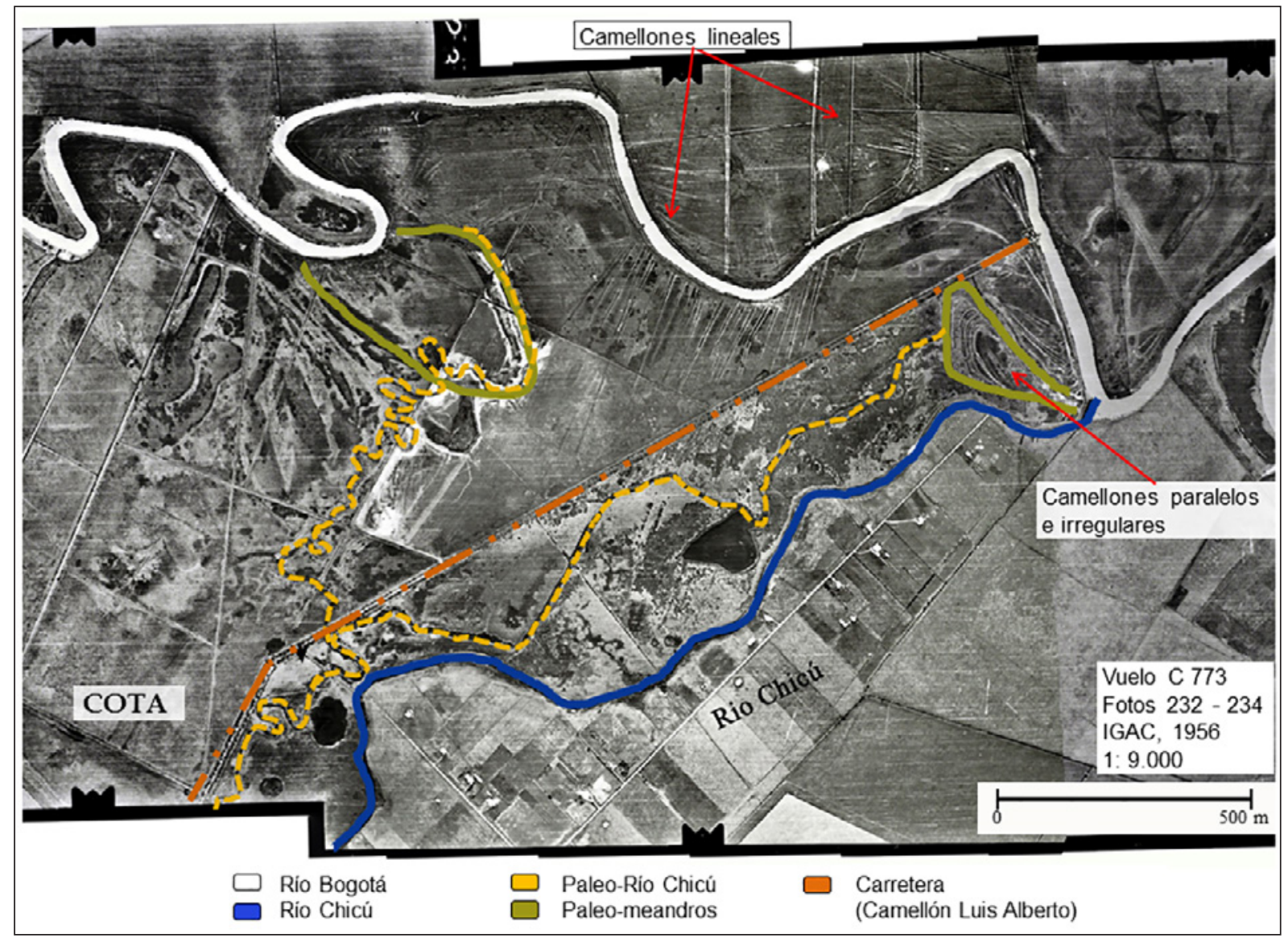

Figura 5. Fotointerpretación de las dinámicas de transformación del valle erosivo del río Chicú.

posteriores a la Conquista, que sin el sistema de manejo de agua, serían de mayores dimensiones, ampliando el área inundada hasta convertirla en un humedal. La carretera llamada "camellón Luis Alberto" limitaría el humedal al norte y el actual río Chicú por el sur.

Este río tiene un lecho un poco más rectilíneo, característico de los ríos jóvenes, sin evidencias de crecimiento o migración de meandros y sin vestigios del sistema hidráulico. Por otro lado, el paleo-curso presenta mayor ondulación, con migración de meandros y lo que es más importante, con evidencias de camellones ajedrezados en su banda izquierda (fig. 2), lo que nos lleva a afirmar que este sería el valle de drenaje prehispánico. A su vez, este paleo-curso se bifurca a la izquierda antes de juntarse con el río Bogotá, creando un valle de erosión que capturó un paleo-meandro pasando a ser su desembocadura en el río Bogotá. También fue identificado un pequeño grupo de camellones en su banda derecha, lo que nos indica que esta bifurcación estaba activa para el final del periodo prehispánico.
¿Dónde estaban los constructores de este paisaje hidráulico? Para el Muisca Tardío, periodo que corresponde a las imágenes del sistema hidráulico, la evidencia arqueológica (O’Neil 1972, Bernal 1990, Boada 2000b, 2006; Kruschek 2003) muestra que los indígenas ocupaban todas estas planicies, tanto en asentamientos dispersos como concentrados alrededor de los cercados de los caciques. En el mapa de distribución del material cultural registrado por Boada (2006: 78) se observan aglomeraciones que sugieren la presencia de aldeas nucleadas junto a los cerros Majuy y Suba, y en el valle aluvial del río Bogotá al norte del humedal La Conejera; sin embargo es tal la concentración de material a lo largo de la planicie que pareciera que formase una gran villa. Esto indica que los Muiscas vivían en los mismos lugares donde cultivaban, y que el sistema hidráulico no solo estaba rodeado de plataformas para el cultivo sino de habitaciones, muchas de ellas instaladas probablemente también en plataformas para evitar los encharcamientos por aguas freáticas. El manejo del 
agua es visible en la amplia presencia de asentamientos en el margen oriental de la llanura aluvial (ibd.).

\subsection{Sector Centro}

A medida que avanzamos hacia el sur observamos algunos cambios en la morfología del sistema hidráulico. Los canales lineales se densifican, lo que se explica porque buena parte de esta planicie está al mismo nivel del río, especialmente a uno y otro lado del meandro El Say. Entre La Florida y el Gualí observamos un promedio de 10 canales cada $150 \mathrm{~m}$, que alcanzan de $800 \mathrm{~m}$ a $900 \mathrm{~m}$ de largo. Sin embargo vemos cómo estos canales fueron interrumpidos abruptamente, por trabajos modernos, siendo trazada una línea transversal que los limita a la llanura aluvial (fig. 6, parte inferior y central izquierda). Esto quiere decir que su longitud debía ser mayor, y extenderse hacia el interior de la planicie. $\mathrm{Su}$ efectividad en el manejo del agua se evidencia en la reducida movilidad del río, que presenta pocos casos de crecimiento y estrangulamiento de meandros, la mayor parte de ellos presentes en El Say.

La evidencia de camellones ajedrezados disminuye drásticamente, registrándose pequeños sectores a lo largo de la banda sur del río Juan Amarillo, en El Cortijo, y en los brazos del Humedal Jaboque. También observamos varias manchas de camellones esparcidas en el sector conformado por los humedales El Burro y Techo, y por los ríos Fucha y San Francisco. Estos elementos, sumados a la presencia de andisols (Van der Hammen 2003), nos indican que la planicie entre el río Juan Amarillo y el antiguo valle de erosión de El Burro debía tener plataformas elevadas para el cultivo.

Los vestigios del sistema hidráulico en la llanura aluvial de este sector están bien preservados, permitiéndonos comprobar que en esta zona, completamente expuesta a las inundaciones, había una gran cantidad de camellones paralelos e irregulares, fundamentalmente en las partes cóncavas de los meandros (en las partes convexas se localizan los canales lineales). ¿Cómo era posible proteger estas estructuras en tierra de las inundaciones? Los vestigios ubicados en el meandro a la derecha del humedal La Conejera nos dan la clave del problema (fig. 3b): los camellones ubicados al interior de los meandros se encontraban protegidos por los canales que, pasando por encima de ellos, dirigían el exceso de agua hacia el interior de la planicie, bien distribuyéndola de forma controlada a través de las estructuras en tierra ajedrezadas (ver Sector Sur) o concentrándola en áreas de mitigación.
En cuanto a los ríos y humedales contemporáneos del sistema hidráulico, encontramos que existía un pequeño valle erosivo que tal vez naciese en la propia planicie y que desembocaba en el meandro de El Cortijo. En las aerofotografías aún es posible ver camellones en su orilla. El humedal Jaboque también debía corresponder a una red de valles erosivos. En algunos de sus brazos vemos camellones internándose en el agua. En el sector donde el humedal confluye con el río Bogotá son visibles canales para drenaje, que indicarían que las inundaciones de esta zona estaban controladas por el sistema hidráulico. Además, en esta misma área han sido identificados en los últimos años por lo menos 19 monolitos (Muñoz 2004), cuya función astronómica o religiosa aún está siendo objeto de discusión, pero que indicaría que originalmente no se trataba de un espacio de aguas abiertas. Los ríos Fucha y San Francisco mantendrían una apariencia similar a la actual (previa a la canalización del San Francisco) y el humedal de El Burro debía pertenecer a una red de valles erosivos que nacería en la propia planicie.

Del lado occidental del río Bogotá las evidencias de cultivo en la planicie son escasas. Nuevamente encontramos pequeños reductos de estructuras en tierra en algunos rincones, como entre los brazos de los humedales La Florida y El Gualí, que estarían indicando que allí hubo plataformas elevadas para el cultivo. En el Gualí comienza la zona más baja de la Sabana y más susceptible a inundaciones. De hecho, aunque esta planicie tiene presencia de andisols, hay grandes manchas de suelos hidromorfos, de andisols-hidromorfos y de inceptisols-hidromorfos, debido a la extensa red de valles de drenaje (Van der Hammen 2003). Sin embargo, la abundancia de material arqueológico encontrado en los alrededores de Funza y Mosquera parece indicar que esta era una zona densamente poblada.

Los estudios paleo-ecológicos de Van der Hammen permitieron evidenciar hasta qué punto los grupos prehispánicos transformaron el paisaje de la Sabana. Los resultados del análisis de polen provenientes de El Gualí mostraron que la confluencia del antiguo valle de drenaje con el Bogotá fue obstruida hace unos 3.000 años, probablemente de forma artificial, cuando se generalizaron las actividades agrícolas en la zona. Toda la columna de sedimentos presenta polen de maíz, lo que indica que el valle de drenaje solo fue obstruido tardíamente, permitiendo la acumulación de sedimento en su lecho (Van der Hammen 2003: 32). ¿Por qué razón los habitantes de la Sabana cortarían el contacto entre El Gualí y el río Bogotá? Como era la zona más baja de la Sabana, debía ser difícil evitar las inundaciones 


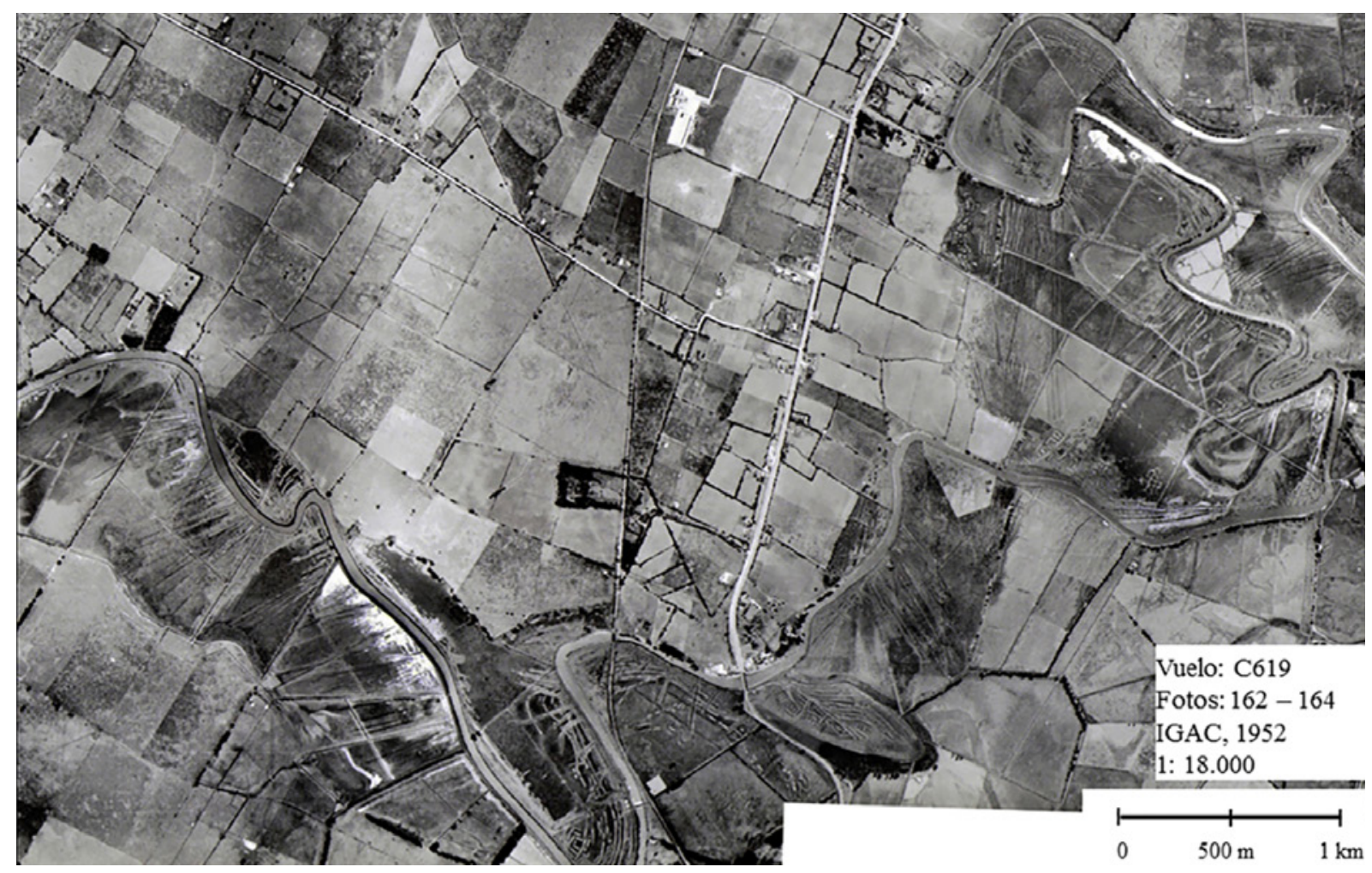

Figura 6. Vista aérea del río Bogotá. Región Engativá-Fontibón. Parte superior derecha: meandro de El Say con camellones lineales e irregulares. Parte inferior central: meandros y paleomeandros con camellones paralelos e irregulares. Parte izquierda: camellones lineales. Actualmente allí se ubica el Aeropuerto El Dorado.

en la planicie de Funza por el desbordamiento de las aguas del río Bogotá a través del valle erosivo de El Gualí. Se debe tener en cuenta que el sistema hidráulico no contaba con muros de contención para controlar las inundaciones. Debieron optar por cerrar el paso del agua desde el río Bogotá hacia El Gualí, dejando fluir el agua de forma controlada hacia la planicie a través de los canales lineales, evitando afectar cultivos y asentamientos.

Un documento colonial nos da la clave de esta deducción: en él se relata la constante destrucción del Camellón de Occidente debido al desbordamiento del río Bogotá a través de los valles erosivos de El Gualí y La Florida (el Camellón de Occidente era la principal vía de acceso a la ciudad por el oeste, a la que se le dio el nombre de camellón por ser una carretera elevada del suelo para evitar que quedara sumergida durante las inundaciones del invierno). La solución sugerida fue terraplenar ambas confluencias.

[...] habiendo preguntado de donde procedían, cuando había lluvias, descargasen las aguas a esta parte [de la planicie], dijeron que de unas zanjas que tiene el río de Bogotá cosa de tres cuartos de legua más arriba de la puente en frente del pueblo de Engativa... y dijeron los presentes que este era el caño por donde iba el agua a la Ciénaga de Bogotá y de lo que ella retumba venía a caer a donde se rompió dicho camellón [de Occidente], y que si fuese conveniente el terraplenar esta quiebra se podía hacer con una estancada sin mucho costo en su boca ...y que bajando por la ronda del rio hacia la puente de Bogotá encontraron otra zanja ...y dijeron los presentes que por esta quiebra o zanja entraba lo más principal del agua cuando crecía el rio... y visto y reconocido pareció fuera conveniente se hiciera una estancada en esta quiebra para... que las aguas que por ella derraman fuesen por el río y no hiciesen tanto daño ... (Testimonio de los Autos... Santa fe: 377 )

Es probable que no fuera esta la primera vez que se planteaba una solución de este tipo, y que la sugerencia fuera producto de usos que remontaban al periodo prehispánico.

El registro arqueológico (Boada 2000b, 2006) continúa mostrando un denso poblamiento. Desde el río Chicú, pasando por los brazos del humedal La Florida y 
de El Gualí hasta Tibaitatá, se encuentran vestigios que sugieren un poblamiento disperso a lo largo de la planicie, con aldeas nucleadas en el borde de las terrazas naturales, junto al río Bogotá en el sector de Vuelta Grande, y al interior de los brazos de El Gualí. El hecho de que este último sector hubiese estado densamente poblado confirma que la desembocadura de El Gualí fue colmatada para impedir el desbordamiento del río Bogotá en este punto (sin descartar el flujo controlado del agua a través de los canales lineales que irradian desde el río Bogotá), propiciando la instalación de asentamientos.

Muchos de estos vestigios están ubicados en los mismos espacios donde se identificaron huellas de camellones. Bernal (1990) y Kruschek (2003) también encontraron sitios arqueológicos con material del Muisca Tardío en La Ramada y El Say, asociados a estas estructuras en tierra. Pero estas transformaciones del espacio natural no indican que el agua haya desaparecido, simplemente fue manejada de forma tal que evitase damnificar cultivos y asentamientos. La red de valles erosivos de La Florida y El Gualí no desapareció, simplemente se evitaba su desbordamiento.

La banda oriental del río es más difícil de interpretar dada la escasez de evidencias arqueológicas. Al interior de la planicie, donde se encontrarían las plataformas elevadas, no hay hasta el momento vestigios de asentamientos, mientras que en las cercanías del río Bogotá se han encontrado tres sitios con material del Muisca Tardío, en el área de influencia de los camellones: en el área urbana de Fontibón (Botiva y Enciso 1998), en la terraza natural de Engativá (Boada 2000b) y al noroeste de El Say (Kruschek 2003). Es probable que existieran áreas de mitigación entre Engativá y Fontibón, pero no podemos ser más concluyentes con los datos disponibles.

\subsection{Sector Sur}

En este sector lo que más destaca es el predominio de los canales lineales en ambas márgenes del río Bogotá y en la parte baja del río Tunjuelito. Sin duda, este sector fue dedicado fundamentalmente a las labores de drenaje. En San Bernardino encontramos canales irradiando tanto de la banda oriental del río Bogotá como de la banda norte del río Tunjuelito, que alcanzan $2 \mathrm{~km}$ de longitud, resguardando la confluencia de grandes inundaciones. Aunque en general los canales tuviesen como función principal drenar el exceso de agua, fueron identificados camellones alternando con los canales que irradian del meandro El Corzo.
En este punto se puede ver que el terreno entre los canales tiene pequeños cortes perpendiculares, que deben corresponder a canales menores que dividen una parcela de cultivo de otra. También verificamos que estos canales de San Bernardino drenaban el agua hacia una pequeña área de cultivo, con camellones en cuadrícula, revelando así que el sistema hidráulico podría tener en algunos puntos específicos la doble función de drenaje-irrigación. Esto es posible dado que la zona sur de la Sabana es más seca, con precipitaciones anuales que no exceden los $1.000 \mathrm{~mm}$ (FAO 2010: 33).

Hay poca presencia de estructuras en tierra tanto en la llanura aluvial como al interior de la planicie. En Soacha fueron identificados algunos camellones en cuadrícula que se proyectan desde el meandro Las Vegas hacia el interior y que tal vez correspondiesen originalmente a camellones ajedrezados. En el medio y alto Tunjuelito no encontramos un sólo trazo que nos indicase la presencia de plataformas de cultivo. Es probable que el sistema hidráulico no se haya extendido hasta aquí, ya que la zona posee suelos poco adecuados para la agricultura. Además, su lecho presenta una fuerte movilidad, con crecimiento, estrangulamiento y desplazamiento de meandros, lo que indica ausencia de un sistema de manejo del agua (Rodríguez Gallo 2011).

En Bosatama encontramos un buen ejemplo de los diferentes momentos de construcción del sistema hidráulico. En las fotografías aéreas (fig. 7) aún es visible un paleo-curso que, según la interpretación de Etayo (2002), correspondería a una antigua confluencia del Tunjuelito con el Bogotá. Desde nuestra perspectiva, el paleo-curso formaba parte exclusivamente de un trecho del río Bogotá, que correría un poco más a sudeste de su posición actual. Desafortunadamente no es posible a través de la fotointerpretación descubrir la antigua confluencia. Lo interesante es que este paleo-curso tiene canales para drenaje aún visibles, lo que quiere decir que este tramo del río perteneció al sistema hidráulico, y que los canales del sector San Bernardino solo fueron construidos en una segunda fase, cuando el río Bogotá efectuó su cambio de curso, ya que la confluencia actual no podía haber existido cuando el paleo-curso se encontraba activo, como se destacó en un trabajo anterior (Rodríguez Gallo 2011).

En el río Balsillas también encontramos pequeños canales en el sector El Tabaco y algunos camellones frente a Mondoñedo. Sin embargo esta región ha sido fuertemente alterada dificultando una reconstrucción más detallada. El lecho serpenteante del río Balsillas fue remplazado por un canal rectilíneo, cambiando 


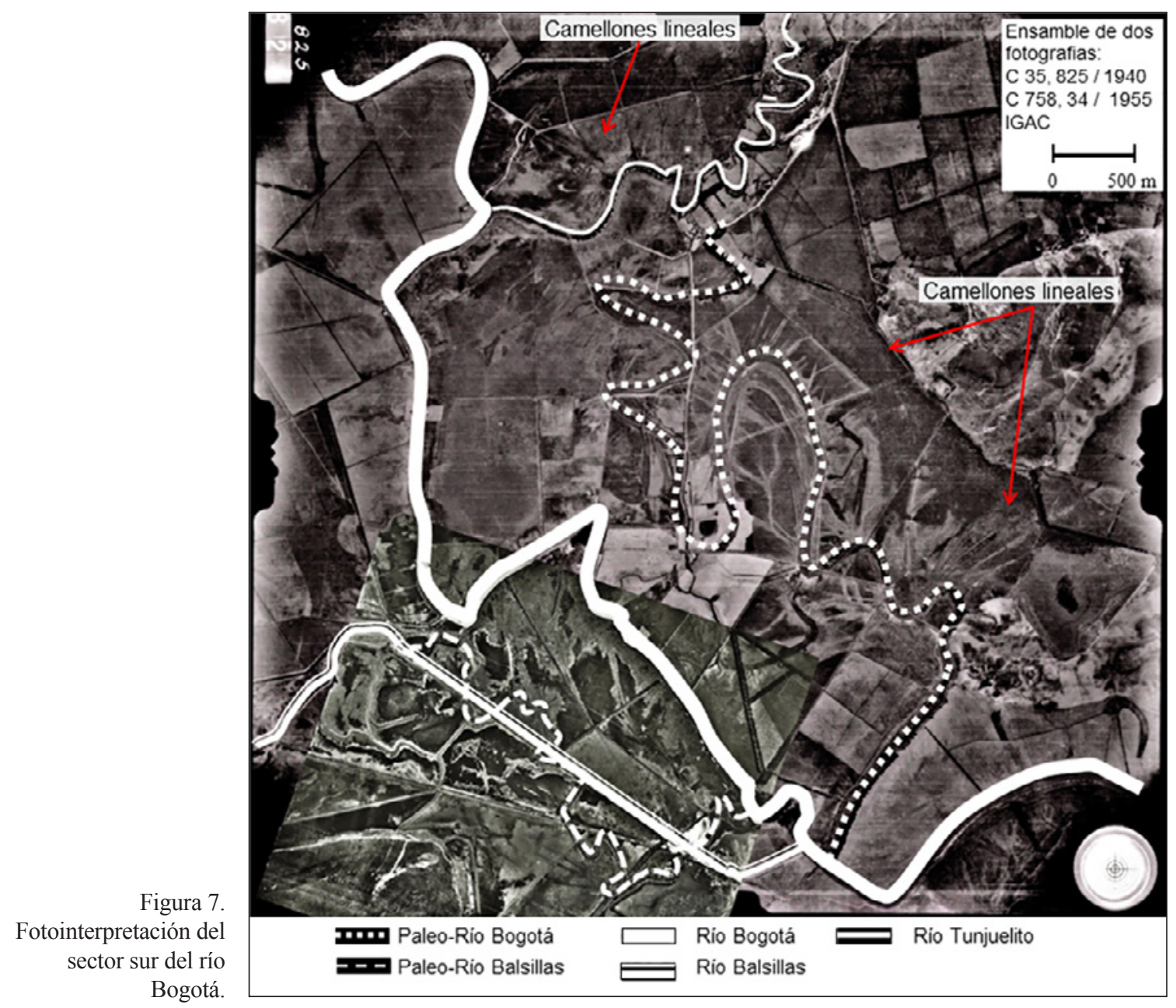

incluso su confluencia con el Bogotá. En medio de este nuevo canal se pueden distinguir restos de los canales del sistema hidráulico. Kruschek (2003) prospectó el área que se encuentra entre Tibaitatá, El Say y El Corzo sin encontrar ningún tipo de material cultural, sin embargo en esta zona del río Bogotá irradian una densa cantidad de canales lineales. Estos dos elementos indicarían que esta debía ser un área de mitigación.

En el valle del río Tunjuelito no hay registros regionales sistemáticos, pero en contrapartida han sido encontrados varios sitios arqueológicos en proyectos principalmente de salvamento arqueológico, que han mostrado un poblamiento denso que se habría iniciado al final del Muisca Temprano. Uno de los descubrimientos más recientes es la necrópolis encontrada en Tibanica con 600 tumbas y más de 15 plantas de habitación pertenecientes al Muisca Temprano y Tardío (Langebaek 2011), que apenas representan una parte del sitio original, ya que los trabajos arqueológicos estuvieron limitados al área de salvamento. Próximas a este local encontramos otras zonas de ocupación en la Hacienda Terreros, donde se registraron 92 tumbas pertenecientes al mismo periodo (Bonilla 2005, 2008). Estos asentamientos estarían en interacción con los cultivos presentes en la zona baja del valle del Tunjuelito. En la zona media y alta del valle, donde no habría cultivos, se desarrolló una intensa actividad textil que se refleja en el registro arqueológico: volantes de uso y agujas para el tejido han sido encontradas en cantidades superiores al resto de la Sabana, lo que podría indicar una especialización en el tejido.

\subsection{No solo de maíz vive el hombre}

El agua también proveía importantes recursos alimenticios. Los ríos, lagunas y humedales abrigaban una 
amplia variedad de animales pequeños como pájaros, patos, roedores, moluscos de agua dulce y pescado; recursos importantes dado que el altiplano no poseía animales de gran porte, salvo los venados que, además, tenían un consumo restringido a los caciques y las personas autorizadas por ellos (Ghisletti 1954 v 2: 79). La pesca era una actividad central en la vida económica de los Muiscas, como lo muestran diversos testimonios en la documentación colonial, en los que se dice que era practicada en las vegas y ríos de Funza (Indios del pueblo de Bogotá... Escribanía de Cámara: 763), «... en el Río de Chinga (actual río Serrezuela) y en las ciénagas que están junto a su pueblo [de Bogotá]...», donde tenían zanjas y corrales (Bernal 1990: 46). Fray Pedro Simón referencia la región de El Tabaco como un sitio importante para la pesca (Simón 1981 [1625] v 2: 254256). Otros documentos también mencionan a Fontibón. Los indios de esta parcialidad declararon en 1605 que tenían «...en el rio de Fontibón ciertos hoyos y pesquería que heredamos de nuestros abuelos y antepasados...» (Langebaek 1987: 72).

¿Cómo desarrollaron esta actividad? Las descripciones no son detalladas, apenas sugieren que, además de la pesca directa, debían criar pescado en corrales. La fotointerpretación podría ayudarnos a aclarar el problema. Erickson (2000) encontró vestigios, visibles en las fotografías aéreas, de estructuras en tierra en Baures (Amazonía Boliviana) que interpretó como un sistema para pesca. Se trata de barreras construidas en las sabanas inundables en forma de zigzag. Algunas tienen una abertura en el vértice a manera de embudo, que conecta con pequeñas lagunas. Durante las inundaciones el pescado quedaría preso en las barreras, siendo dirigido hacia los reservorios a través del embudo.

En el caso de la Sabana de Bogotá no obtuvimos resultados satisfactorios con la fotointerpretación. Autores como Broadbent (1968) y Bernal (1990) sugirieron que los propios canales del sistema de camellones pudieron ser usados para la cría de peces. Esto no nos parece probable dado que no es agua corriente, y debido a la dificultad de mantener un volumen de agua suficiente pasadas las inundaciones (Boada 2006). Es más probable que en la época de subienda hubiese una pesca "oportunista", que consistía en aprovechar el pescado que quedaba atrapado entre los canales del sistema hidráulico. Los canales también podían ser aprovechados para desviar el pescado hacia humedales, lagunas o pozos con agua corriente (áreas de mitigación tal vez), donde pudiese ser almacenado y donde se practicase algún tipo de piscicultura, como lo sugiere la documentación colonial.
La toponimia de la Sabana abunda en palabras derivadas del vocablo chucua, de origen muisca, que significa pesquería o pantano (Acosta 1938: 33), lo que nos podría dar una indicación por lo menos de los lugares donde la pesca era practicada. Según los mapas del IGAC (1940 y 1994) en Tibabuyes, El Gualí y La Florida existían lugares con el nombre Chucua. En el lado sur de la antigua confluencia del Gualí con el Bogotá había una hacienda llamada La Pesquera y un poco más al sur, debajo del meandro de El Say un sitio llamado Pesquerita. Este topónimo abunda en Soacha, especialmente en la región de El Tabaco y en Bosatama, donde encontramos dos lugares con el nombre La Chucua y otros llamados La Chucuita, Chucuaviva, Hacienda La Chucuapuyana y un último llamado La Pesquera, sitios que se corresponden con los datos de la documentación colonial.

Vestigios arqueológicos de pez capitán, capitán enano, guapucha, ostras y cangrejos de agua dulce fueron encontrados en Aguazuque, así como pesos para redes de pesca (Correal 1990). En el valle del río Tunjuelito también se encontraron restos de este tipo de fauna, herramientas para el tejido hechas con hueso de pescado o herramientas para la pesca (arpones) hechas con hueso de venado (Enciso 1996: 41-58). Estos datos nos llevan a entender que a lo largo de toda la Sabana había sitios de pesca que interactuaban con el sistema hidráulico. Los ríos, lagos y humedales eran locales importantes para el desarrollo de esta actividad, ayudados probablemente por los canales del sistema hidráulico como medios para captar los peces durante la subienda.

\section{CONCLUSIONES}

La Sabana de Bogotá pasó por varios momentos de profundas transformaciones, naturales y antrópicas, que la llevaron a convertirse durante la fase agrícola del periodo prehispánico en una altiplanicie cubierta por canales y plataformas elevadas, donde el maíz, el frijol y los tubérculos proliferaron. Las generaciones de personas que siguieron a la primera oleada, llegada hace 12.400 años de las tierras bajas, acumularon un vasto conocimiento del ambiente ecológico que habitaban. La comprensión de esa naturaleza, siempre fría, siempre inundable, les permitió transformarla progresivamente hasta convertir su principal dificultad, el agua, en un elemento central de su cotidianidad.

El análisis realizado nos permite concluir que para el Muisca Tardío, el paisaje de la Sabana de Bogotá estaba constituido por un sistema de redes de canales que 
controlaban el agua de los ríos y las inundaciones causadas por alto nivel freático; en plataformas elevadas para el cultivo que se extendían por toda la planicie, sobre terrazas naturales y en los valles aluviales; en áreas de mitigación para donde eran dirigidos los excesos de agua durante el invierno; en asentamientos, nucleados o dispersos, ubicados en medio de los cultivos y alrededor de los Cercados; y en áreas de caza y pesca, localizadas en ríos, humedales, lagunas y, transitoriamente, en los canales del sistema de drenaje. Este paisaje, construido a lo largo de los siglos, hizo del agua una red de interconexión que integró las necesidades humanas con las limitaciones impuestas por la estructura ecológica. Para lograrlo fue necesario llevar a cabo fuertes transformaciones como la deforestación para despejar extensas áreas para el cultivo, la obstrucción de valles erosivos para minimizar los efectos de las inundaciones o el anegamiento estacional de extensas áreas.

En su fase final, podemos ver a los Muiscas viviendo tanto en las faldas de los cerros de Suba, Cota, Soacha, y los demás que circundan la Sabana, como en las terrazas naturales de llanuras aluviales como la del río Tunjuelito, en la planicie y en la propia llanura aluvial del río Bogotá. Varios de estos asentamientos se encuentran en medio de los campos de cultivo, muchas veces compartiendo el espacio con los camellones ajedrezados, otras veces con los irregulares y paralelos a la línea del agua en la vega del río Bogotá. A su lado, grandes canales garantizaban que el agua mantuviese el curso trazado por los muiscas para evitar que afectase a los cultivos y casas, en cuanto que alrededor espejos de agua, estacionales o permanentes, eran aprovechados para desarrollar actividades como la caza y la pesca.

Aunque esta forma de explotación procuró favorecer los intereses de los grupos prehispánicos y del medio ecológico, no podemos afirmar que se tratase de un sistema en equilibrio, sino contingente, sometido a constantes procesos de transformación. Inundaciones de grandes proporciones podrían obligar a ampliar áreas de mitigación, a ampliar la red de canales existentes para garantizar un mejor control en el futuro y a reconstruir plataformas, pero al mismo tiempo eran una oportunidad para obtener mejores resultados en la pesca o en la caza en ambientes lacustres. Las sequías prolongadas también debían obligar a reorganizar una cotidianidad que en buena medida dependía del agua.

Agradecimientos: En este artículo se presentaron parte de los resultados obtenidos en la tesis de doctorado "Água e paisagem agrícola entre os grupos pré-hispânicos da Sabana de Bogotá-Colômbia, defendida en el Museu de Arqueologia e Etnologia, de la Universidad de São Paulo en junio de 2015. Por lo tanto, extiendo mi agradecimiento a las entidades y personas que lo hicieron posible: a la embajada de Brasil en Colombia, que facilitó los mecanismos para la obtención de la beca de estudios doctorales PEC-PG, a la Agencia de fomento CAPES, Brasil, quien apoyó financieramente mi doctorado a través de la beca PECPG (2011-2015), al Museo de Arqueología y Etnología de la Universidad de Sao Paulo por brindarme el espacio académico y de discusión para la realización de la investigación, a la Doctora María Cristina Mineiro Scatamacchia (Universidad de São Paulo) por su asesoría científica y al Doctor Gustavo Portocarrero por la discusión y revisión crítica de la investigación.

\section{ANEXO 1}

Fotografías aéreas analizadas

IGAC (Septiembre de 1938): Vuelo A-27. Sobre 401, escala 1:24.000.

IGAC (Septiembre de 1938): Vuelo A-27. Sobre 402, escala 1: 24.000 .

IGAC (Marzo de 1940): Vuelo C-35. Sobre 843, escala 1: 22.000 .

IGAC (Marzo de 1940): Vuelo C-35. Sobre 844, escala 1: 22.000 .

IGAC (Marzo de 1940): Vuelo C-36. Sobre 845, escala 1: 22.000

IGAC (Diciembre de 1949): Vuelo C-525. Sobre 2280, escala 1: 20.000 .

IGAC (Diciembre de 1949): Vuelo C-525. Sobre 2281, escala 1: 20.000.

IGAC (Diciembre de 1949): Vuelo C-525. Sobre 2282, escala 1: 20.000 .

IGAC (Diciembre de 1949): Vuelo C-525. Sobre 2283, escala 1: 20.000 .

IGAC (Junio de 1950): Vuelo C-549. Sobre 2376, escala 1: 25.000 .

IGAC (Junio de 1950): Vuelo C-550. Sobre 2380, escala 1: 10.000 .

IGAC (Junio de 1950): Vuelo C-550. Sobre 2382, escala 1: 10.000 .

IGAC (Octubre de 1951): Vuelo C-604. Sobre 2704, escala 1: 15.000 .

IGAC (Octubre de 1951): Vuelo C-105. Sobre 2711, escala 1: 20.000 .

IGAC (Octubre de 1951): Vuelo C-605. Sobre 2712, escala 1: 20.000 .

IGAC (Diciembre de 1951): Vuelo C-606. Sobre 2720, escala 1: 20.000 . 
IGAC (Diciembre de 1951): Vuelo C-606. Sobre 2721, escala 1: 20.000

IGAC (Marzo de 1952): Vuelo C-619. Sobres: de 20015 a 20022, escala 1: 18.000.

IGAC (Marzo de 1952): Vuelo C-620. Sobre 20024, escala 1: 18.000 .

IGAC (Septiembre de 1952): Vuelo B-99. Sobre 10420, escala 1: 4.000 .

IGAC (Septiembre de 1952): Vuelo B-100. Sobre 10425, escala 1: 4.000.

IGAC (Enero de 1955): Vuelo C-742. Sobres: de 2850 a 2854, escala 1: 9.000 .

IGAC (Enero de 1955): Vuelo C-742. Sobre 2856, escala 1: 9.000

IGAC (Junio de 1955): Vuelo C-754. Sobres: de 2873 a 2879, escala 1:9.000.

IGAC (Noviembre de 1955): Vuelo C-758. Sobre 20874, escala 1: 7.000 .

IGAC (Noviembre de 1955): Vuelo C-758. Sobre 20876, escala 1: 7.000 .

IGAC (Enero de 1956): Vuelo C-769. Sobre 2913, escala 1: 9.000 .

IGAC (Enero de 1956): Vuelo C-770. Sobre 2927, escala 1: 9.000 .

IGAC (Febrero de 1956): Vuelo C-772. Sobre 2935, escala 1: 9.000 .

IGAC (Febrero de 1956): Vuelo C-773. Sobres: de 2940 a 2946, escala 1: 9.000.

IGAC (Mayo de 1956): Vuelo C-778. Sobre 2962, escala 1: 3.000 .

IGAC (Noviembre de 1956): Vuelo C-790. Sobre 20998, escala 1: 13.000 .

IGAC (Noviembre de 1956): Vuelo C-790. Sobre 20999, escala 1: 13.000 .

* IGAC: Instituto Geográfico Agustín Codazzi

\section{BIBLIOGRAFÍA}

Aguado, P. (Fray) (1957) [1582]: Noticias Historiales de las conquistas de tierra firme en las Indias Occidentales. Bogotá, Empresa Nacional de Publicaciones.

Ardila, G. (1984): Chía, un sitio precerámico en la Sabana de Bogotá. Bogotá, Fondo de Investigaciones Arqueológicas Nacionales - Banco de la República.

Balée, W. (ed.) (1998): Advances in historical ecology. New York, Columbia University Press.

Balée, W. y Erickson, C. (eds.) (2006): Time and complexity in historical ecology, studies in the neotropical lowlands. New York, Columbia University Press.
Bandy, M. (2005): "Energetic efficiency and political expediency in Titicaca Basin raised field agriculture". Journal of Anthropological Archaeology 24: 271-296. https://doi.org/10.1016/j.jaa.2005.03.002

Bernal, F. (1990): "Investigaciones arqueológicas en el antiguo cacicazgo de Bogotá (Funza-Cundinamarca)". Boletín de Arqueología 5 (3): 31-46.

Berrío, J. C. (2006): “Análisis de polen de los camellones Guaymaral y la Filomena, Suba”, en A. M. Boada, Patrones de asentamiento regional y sistemas de agricultura intensiva en Cota y Suba, Sabana de Bogotá (Colombia): 109-131. Bogotá, Fondo de Investigaciones Arqueológicas Nacionales-Banco de la República.

Boada, A. M. (2000a): "Variabilidad mortuoria y organización social Muisca en el sur de la Sabana de Bogotá”, en B. Enciso y M. Therrien (eds.), Sociedades complejas en la Sabana de Bogotá. Siglos VII al XVI D.C.: 21-43. Bogotá, ICANH-Ministerio de Cultura.

Boada, A. M. (2000b): Patterns of regional organization in the Sabana de Bogotá: Colombia. Funza, Mosquera and Fontibón municipios. Pittsburgh, Heinz Foundation Report.

Boada, A. M. (2006): Patrones de asentamiento regional y sistemas de agricultura intensiva en Cota y Suba, Sabana de Bogotá (Colombia). Bogotá, Fondo de Investigaciones Arqueológicas Nacionales-Banco de la República.

Bonilla, M. J. (2005): Programa de prospección, rescate y monitoreo para el lote de desarrollo urbanístico 2, manzana C2 urbanización. San Mateo segunda etapa, Soacha Cundinamarca. Informe. Bogotá, ICANH, Registro ARQ 0954.

Bonilla, M. J. (2008): Proyecto, Prospección, rescate $y$ monitoreo de la manzana E3 y prospección y rescate de las manzanas P1, H1 y G1. Terragrande 2. Hacienda Terreros, Soacha, Cundinamarca. Informe. Bogotá, ICANH, Registro ARQ 1203.

Botiva, A. (1988): "Pérdida y rescate del Patrimonio Arqueológico Nacional". Arqueología. Revista de estudiantes de Antropología 1(5): 3-35.

Botiva, A. y Enciso, B. (1998): Informe de la Comisión de reconocimiento arqueológico en Fontibón. Bogotá, ICANH.

Broadbent, S. (1961): "Excavaciones en Tunjuelito: informe preliminar". Revista Colombiana de Antropología 10: 341-346.

Broadbent, S. (1966): The site of Chibcha Bogotá. Berkeley, Institute of Andean Studies.

Broadbent, S. (1968): “A prehistoric field system in Chibcha territory, Colombia. Nawpa Pacha. Journal 
of Andean Archaeology 6: 135-147. https://doi. org/10.1179/naw.1968.6.1.007

Broadbent, S. (1971): “Reconocimientos arqueológicos de la laguna de La Herrera. Revista Colombiana de Antropología 15: 171-208.

Cadudal, F. (2007): Camellones y Sistemas Agrícolas Prehispánicos de las tierras bajas de la costa del norte del Ecuador. Disponible en http://www.Arqueo-Ecuatoriana.Ec/Es/Articulos [01/07/2014]

Cardale, M. (1981): Las salinas de Zipaquirá. Su explotación indígena. Bogotá, Fondo de Investigaciones Arqueológicas Nacionales-Banco de la República

Correal, G. (1990): Aguazuque: evidencias de cazadores, recolectores y plantadores en la altiplanicie de la Cordillera Orieliaental. Bogotá, Fondo de Investigaciones Arqueológicas Nacionales-Banco de la República.

Correal, G y Pinto, M. (1983): Investigaciones arqueológicas en el municipio de Zipacón, Cundinamarca. Bogotá, Fondo de Investigaciones Arqueológicas Nacionales.

Correal, G. y Van der Hammen, T. (1977): Investigaciones arqueológicas en los abrigos rocosos del Tequendama. 11.000 años de prehistoria en la Sabana de Bogotá. Bogotá, Banco de la República.

Correal, G.; Van der Hammen, T. y Lerman, J. (1969): "Artefactos líticos de abrigo rocoso en el Abra". Revista colombiana de antropología 14: 9-46.

Correal, G.; Van der Hammen, T. y Van Klinken. (1990): "Isótopos estables y dieta del hombre prehistórico en la Sabana de Bogotá (un estudio inicial)". Boletín de Arqueología 5(2): 3-10.

Crumley, C. (ed.). (1994): Historical Ecology: Cultural Knowledge and Changing Landscapes. Satan $\mathrm{Fe}$, School of American Research Press.

Crumley, C. (2007): "Historical Ecology: Integrated Thinking at Multiple Temporal and Spatial Scales", en A. Hornborg, y C. Crumley (eds.), The World System and The Earth System: Global Socio-Environmental Change and Sustainability Since the Neolithic: 15-28. Walnut Creek, Left Coast Press.

Delgado-Espinoza, F. (2002): Intensive Agriculture and Political Economy in the Yaguachi Chiefdom of the lower Guayas Basin, Coastal Ecuador. Tesis doctoral, University of Pittsburgh. Inédita. Disponible en http://d-scholarship.pitt.edu/7649/6/Texto. pdf [17/03/2014]

Denevan, W. (1970): “Aboriginal drained-field cultivation in the Americas". Science 169(3946): 647-654. DOI: $10.1126 /$ science.169.3946.647
Denevan, W.; Hamilton, P. y Smith, C. (1968): “Ancient ridged fields in the region of Lake Titicaca". The Geographical Journal 134(3): 353-367. DOI: 10.2307/1792964

Enciso, B. (1990): “Arqueología de rescate en el barrio Las Delicias (Bogotá)". Revista Colombiana de Antropología 28: 155-160.

Enciso, B. (1996): "Fauna asociada a tres asentamientos muiscas del sur de la Sabana de Bogotá, siglos VIII al XIV d.C", en B. Enciso y M. Therrien (eds.), Bioantropología de la Sabana de Bogotá: siglos VIII al XVI D.C.: 4-58. Bogotá, ICANH-Ministerio de Cultura.

Erickson, C. (1988): An archaeological investigation of raised field agriculture in the Lake Titicaca basin of Perú. Tesis doctoral, University of Illinois. Inédita. Disponible en https://www.academia.edu/23628195/1988_An_Archaeological_Investigation_of_Raised_Field_Agriculture_in_the Lake_Titicaca_Basin_of_Peru [21/11/2013]

Erickson, C. (1993): "The social organization of prehispanic raised fields agriculture in the Lake Titicaca Basin", en V. Scarborough y B. Isaac, Research in economic anthropology. Sup. 7: Economic aspects of water management in the prehispanic new world: 369-426. London, Jay Press Inc.

Erickson, C. (2000): "An artificial landscape-scale fishery in the Bolivian Amanzon". Nature 408: 190193. DOI: $10.1038 / 35041555$.

Erickson, C. (2010): “The transformation of environment into landscape: The historical ecology of monumental earthwork construction in the Bolivian Amazon". Diversity 2: 618-652. DOI: 10.3390/ d2040619

Etayo, M. (2002): Evolución Morfológica del Río Bogotá durante la Parte Superior del Holoceno entre los municipios de Cota y Soacha (Sabana de Bogotá) y su relación con los "camellones” prehispánicos. Tesis de grado, Universidad Nacional de Colombia. Inédita.

FAO (2010): Análisis de los sistemas de producción agrícola de las Provincias de Soacha y Sumapaz (Cundinamarca). Documento de Trabajo. Bogotá, FAO.

Friede, J. (1960?): Descubrimiento del Nuevo Reino de Granada y Fundación de Bogotá. 1536-1539. Bogotá, Banco de la República.

Gamboa, J. (2008): "Las instituciones indígenas de gobierno en los años posteriores a la Conquista: caciques y capitanes muiscas del Nuevo Reino de Granada (1537-1650)", en C. Valencia y F. Alzate 
(eds.), Imperios ibéricos en comarcas americanas: estudios regionales de la historia colonial brasilera y neogranadina: 136-164. Bogotá, Editorial Universidad del Rosario.

Ghisletti, L. (1954): Los Mwiskas. Una gran civilización precolombina. 2 Tomos. Bogotá, Revista Bolívar-Ministerio de Educación Nacional.

Graffam, G. (1990): Raised Fields without bureaucracy: an archaeological examination of intensive wetland cultivation in the Pampa Koani zone, lake Titicaca, Bolivia. Tesis doctoral, University of Toronto. Inédita. Disponible en https://www.researchgate.net/ publication/34819008_Raised_Fields_without_Bureaucracy_An_Archaeological_Examination_of_ Intensive_Wetland_Cultivation_in_the_Pampa Koani Zone Lake Titicaca Bolivia

Gassón, R. (1998): Prehispanic intensive agriculture, settlement pattern and Political economy in the western venezuelan llanos. Tesis doctoral, University of Pittsburgh. Inédita. Disponible en https://www.academia.edu/33675921/Prehispanic_intensive_agriculture_settlement_pattern and_political_economy_in_the_western_Venezuelan_Llanos

Groot, A. M. (1992): Checua: una secuencia cultural entre 8500 y 3000 años antes del presente. Bogotá, Fondo de Investigaciones Arqueológicas Nacionales-Banco de la República.

Gutiérrez, S. y García, L. (1985): Arqueología de Rescate, Funza III. Informe. Bogotá, Biblioteca Luis Ángel Arango. Registro 930.1 A76g.

Hammond, N. (1984): "Raised-Field Farming in Mesoamerica". Science 224 (4650): 741-743. DOI: 10.1126/science.224.4650.741

Haury, E. y Cubillos, J. C. (1953): “Investigaciones arqueológicas en la Sabana de Bogotá, Colombia. Cultura Chibcha". Social Science Bulletin, 24 (2): 5-104. https://doi.org/10.2307/276187

Kruschek, M. (2003): The evolution of the Bogota Chiefdom: a household view. Tesis doctoral, University of Pittsburgh. Inédita. Disponible en. http://d-scholarship.pitt.edu/7735/

Langebaek, C. (1987): Mercados, poblamiento e integración étnica entre los Muiscas. Siglo XVI. Bogotá, Banco de la República.

Langebaek, C. (2011): Plan de normalización del estudio arqueológico, Alameda Tibanica. Informe. Bogotá, ICANH. Registro ARQ 2065.

McIntosh, R. (2005): Ancient middle Niger. Urbanism and the self-organization landscape. Cambridge, Cambridge University Press.
Moreno, L. y Cifuentes, A. (1987): Proyecto de Arqueología de Rescate de la Avenida Villavicencio (Candelaria la Nueva). Informe. Bogotá, ICAN. Registro ARQ 0136.

Muñoz Barrera, J. (2004): Humedal de Jaboque: evolución geomorfológica y geológica; y su relación con las culturas prehispánicas. Tesis de grado, Universidad Nacional de Colombia. Inédita. Disponible en https://www.researchgate. net/publication/281198288_Humedal_Jaboque_ evolucion_geomorfologica_y_geologica_y_su_relacion_con_las_culturas_prehispanicas.

O'Neil, D. (1972): San Jorge a late terraced site on the Sabana de Bogotá Colombia. Tesis doctoral, University of California. Inédita. Disponible en https:// www.researchgate.net/publication/35739459_San Jorge_microform_a_late terraced_site_on_the_Sabana_de_Bogota_Colombia

Parcak, S. (2009): Satellite Remote Sensing for archaeology. London, Routledge.

Parsons J. (1970): "Los campos de cultivo prehispánicos del bajo San Jorge". Revista de la Academia de Ciencias Exactas Físicas y Naturales 12 (48): 449-458.

Parsons, J. y Bowen, W. (1966): “Ancient ridged fields of the San Jorge river floodplain, Colombia". The Geographical Review 56: 317-143. DOI: $10.2307 / 212460$

Peña, G. (1988): “Contribución al estudio de los periodos cerámicos en el altiplano cundiboyacense y su vertiente suroccidental". Boletín de Arqueología 3(3): 32-56.

Pérez Preciado, A. (2000): La estructura ecológica principal de la Sabana de Bogotá. Bogotá, Sociedad Geográfica de Colombia.

Pinto, M. (2003): Galindo, un sitio a cielo abierto de cazadores/recolectores en la sabana de Bogotá (Colombia). Bogotá, Fondo de Investigaciones Arqueológicas Nacionales-Banco de la República.

Plafker, G. (1964): "For a description of the drainage of the Beni basin". Geological Society of America Bulletin 75: 503.

Plazas, C. y Falchetti, A. M. (1986): "La cultura del oro y el agua: un proyecto de reconstrucción". Boletín cultural y bibliográfico 23 (6): 57-72.

Plazas, C.; Falchetti, A. M.; Van der Hammen, T. y Botero, P. (1988): "Cambios ambientales y desarrollo cultural en el bajo río San Jorge". Boletín Museo del Oro 20: 54-88.

Plazas, C.; Falchetti, A. M.; Sáenz, J y Archila, S. (1993): La sociedad hidráulica Zenú: estudio 
arqueológico de 2000 años de historia en las llanuras del Caribe colombiano. Bogotá, Museo del oroBanco de la República.

Portocarrero, G. (2010): Braga na idade moderna: Paisagem e Identidade. Tomar, CEIPHAR.

Reichel-Dolmatoff, G. (1943): “Apuntes Arqueológicos de Soacha". Revista del Instituto Etnológico Nacional 1: 15-25.

Rodríguez Cuenca, J. V. (2011): Los Chibchas, hijos del sol, la luna y los andes. Orígenes de su diversidad. Bogotá, Universidad Nacional-Alcaldía Mayor de Bogotá.

Rodríguez Cuenca, J. y Cifuentes, A. (2005): “Un yacimiento formativo ritual en el entorno de la antigua laguna de la Herrera, Madrid, Cundinamarca". Maguaré 19: 101-131.

Rodríguez Gallo, L. (2011): Cultivos de agua. La experiencia prehispánica en la Sabana de Bogotá. Sistema de camellones en el valle de los ríos Tunjuelito y Bogotá. Saarbrucken, LAP Lambert - Editorial Académica Española.

Rodríguez Gallo, L. (2015): Água e paisagem agrícola entre os grupos pré-hispânicos da Sabana de Bogotá, Colômbia. Tesis doctoral, Universidade de São Paulo. Inédita. Disponible en http://www.teses. usp.br/teses/disponiveis/71/71131/tde-06082015144204/pt-br.php

Romano, F. (2003): "San Carlos: Documentando trayectorias evolutivas de la organización social de unidades domésticas en un cacicazgo de la Sabana de Bogotá. (Funza, Cundinamarca)". Boletín de Arqueología 18: 3-51.

Simón, P. (Fray) (1981) [1625]: Noticias Historiales de las conquistas de Tierra Firme en las Indias Occidentales. 6 tomos. Bogotá, Banco Popular.

Schaan, D. (2012): Sacred geographies of ancient Amazonia. Historical ecology of social complexity. California, Left Coast Press.

Siemens, A. (1983): "Oriented raised fields in Central Veracruz”. American Antiquity 48 (1): 85-102. DOI: $10.2307 / 279821$
Sin autor (1576-1687): Indios de Cota contra Diego de Larrota sobre tierras. Archivo General de Indias. Escribanía de Cámara, 840A.

Sin autor (1597): Indios del pueblo de Bogotá. Exposición de Francisco Maldonado de Mendoza, sobre los daños que causaba la estación lluviosa en las tierras. Archivo General de Indias. Escribanía de Cámara, 763, legajo 55, folio 711-721.

Smith, N. (2014): Palms and people in the Amazon. Geobotany Studies. Basics, methods and case studies. New York, Springer.

Sturtevant, W. (1961): "Taino Agriculture", en J. Wilbert (ed.), Antropologica, supplement publication, n.2. The evolution of horticultural systems in native South America causes and consequences. A symposium: 69-82. Caracas, Sociedad de ciencias naturales La Salle.

Testimonio de los Autos obrados sobre los aliños del puente de Bogotá, Camellón de las Alcantarillas. (1704). Archivo General de Indias. Santa fe, 377, expediente de Salvador Ricaurte, folio 268.

Valdéz, F. (ed.) (2006): Agricultura ancestral. Camellones y albarradas: Contexto social, usos y retos del pasado y del presente. Quito, Abya-Yala.

Van der Hammen, T. (ed.) (1992): Historia, ecología y vegetación. Bogotá, Banco Popular-COA.

Van der Hammen, T. (1995): "La última glaciación en Colombia”. Análisis Geográficos: 24, 69-90.

Van der Hammen, T. (2003): "Los humedales de la Sabana. Origen, evolución, degradación y restauración", en Empresa de Acueducto y Alcantarillado de Bogotá, Los humedales de Bogotá y la Sabana: 19-48. Bogotá, Acueducto de Bogotá.

Velandia, R. (1979-1982): Enciclopédia histórica de Cundinamarca. 5 tomos. Bogotá, Biblioteca de Autores Cundinamarqueses.

Whitehead, N. (1998): "Ecological History and Historical Ecology: Diachronic Modeling vs. Historical Explanation", en W. Balée (ed.), Advances in Historical Ecology: 43-66. New York, Columbia University Press. 
